\title{
Mitochondrial ATP-Mg/Pi Carrier SCaMC-3/Slc25a23 Counteracts PARP-1-Dependent Fall in Mitochondrial ATP Caused by Excitotoxic Insults in Neurons
}

\author{
(1)Carlos B. Rueda, ${ }^{1,2,3 *}$ Javier Traba, ${ }^{1,2,3 *}$ Ignacio Amigo, ${ }^{1,2,3 *}$ Irene Llorente-Folch, ${ }^{1,2,3}$ Paloma González-Sánchez, ${ }^{1,2,3}$ \\ Beatriz Pardo, ${ }^{1,2,3}$ José A. Esteban, ${ }^{1}$ Araceli del Arco, ${ }^{2,3,4}$ and Jorgina Satrústegui ${ }^{1,2,3}$ \\ ${ }^{1}$ Departamento de Biología Molecular, Centro de Biología Molecular Severo Ochoa, Consejo Superior de Investigaciones Científicas-Universidad Autónoma \\ de Madrid, 28049 Madrid, Spain, ${ }^{2}$ Centro de Investigación Biomédica en Red de Enfermedades Raras, 28029 Madrid, Spain, ${ }^{3}$ Instituto de Investigación \\ Sanitaria Fundación Jiménez Díaz, 28006 Madrid, Spain, and ${ }^{4}$ Centro Regional de Investigaciones Biomédicas, Facultad de Ciencias Ambientales y \\ Bioquímica, Universidad de Castilla La Mancha, 45600 Toledo, Spain
}

Glutamate excitotoxicity is caused by sustained activation of neuronal NMDA receptors causing a large $\mathrm{Ca}^{2+}$ and $\mathrm{Na}^{+}$influx, activation of poly(ADP ribose) polymerase-1 (PARP-1), and delayed $\mathrm{Ca}^{2+}$ deregulation. Mitochondria undergo early changes in membrane potential during excitotoxicity, but their precise role in these events is still controversial. Using primary cortical neurons derived from mice, we show that NMDA exposure results in a rapid fall in mitochondrial ATP in neurons deficient in SCaMC-3/Slc25a23, a Ca ${ }^{2+}$-regulated mitochondrial ATP-Mg/Pi carrier. This fall is associated with blunted increases in respiration and a delayed decrease in cytosolic ATP levels, which are prevented by PARP-1 inhibitors or by SCaMC-3 activity promoting adenine nucleotide uptake into mitochondria. SCaMC-3 KO neurons show an earlier delayed $\mathrm{Ca}^{2+}$ deregulation, and SCaMC-3-deficient mitochondria incubated with ADP or ATP-Mg had reduced $\mathrm{Ca}^{2+}$ retention capacity, suggesting a failure to maintain matrix adenine nucleotides as a cause for premature delayed $\mathrm{Ca}^{2+}$ deregulation. SCaMC-3 KO neurons have higher vulnerability to in vitro excitotoxicity, and SCaMC-3 KO mice are more susceptible to kainate-induced seizures, showing that early PARP-1-dependent fall in mitochondrial ATP levels, counteracted by SCaMC-3, is an early step in the excitotoxic cascade.

Key words: ATP-Mg/Pi carrier; calcium; excitotoxicity; mitochondria; PARP-1; SCaMC-3

\section{Introduction}

Glutamate (Glu) is the main excitatory neurotransmitter of the CNS, but at micromolar concentrations it triggers neuronal

\section{Received July 3, 2014; revised Dec. 9, 2014; accepted Dec. 17, 2014}

Author contributions: C.B.R., J.T., I.A., B.P., J.A.E., A.d.A., and J.S. designed research; C.B.R., J.T., I.A., and I.L.-F. performed research; A.d.A. contributed unpublished reagents/analytic tools; C.B.R., J.T., I.A., I.L.-F., P.G.-S., J.A.E., and A.d.A. analyzed data; C.B.R., A.d.A., and J.S. wrote the paper.

This work was supported by Ministerio de Economía Grant BFU2011-30456, by Centro de Investigación Biomédica en Red de Enfermedades Raras [an initiative of the Instituto de Salud Carlos III (ISCIII)], by Comunidad de Madrid Grant S2010/BMD-2402 MITOLAB-CM (to J.S.), by ISCIII Grant PI080610 (to A.d.A.), and by an institutional grant from the Fundación Ramon Areces to the Centro de Biología Molecular Severo Ochoa. C.B.R. is the recipient of an Formacion Personal Universitario fellowship from the Ministerio de Educación y Ciencia. P.G.-S. is a recipient of a Formacion Personal Investigador-UAM fellowship from Universidad Autónoma de Madrid. We thank Dr Hiromi Imamura, Kyoto University, for providing the GO-ATeam plasmids. We also thank Dr. Paola Boloventa for the PCAGGS expression plasmid. In addition, we thank Isabel Manso, Alejandro Arandilla, and Bárbara Sesé for technical support; María Angeles Muñoz, from the Unit of Optical and Confocal Microscopy, for her inestimable support; and Dr. Laura Formentini for her help with polyADP-ribose detection experiments.

*C.B.R., J.T., and I.A. contributed equally to this work.

The authors declare no conflicting financial interests.

Correspondence should be addressed to Dr. Jorgina Satrústegui, Departamento de Biología Molecular, Centro de Biología Molecular Severo Ochoa, Consejo Superior de Investigaciones Cientíicas-Universidad Autónoma de Madrid-(CSICUAM), Nicolas Cabrera, 1, 28049 Madrid, Spain. E-mail: jsatrustegui@cbm.csic.es.

J. Traba's present address: Cardiovascular and Pulmonary Branch, NHLBI, NIH, Bethesda, MD 20892.

I. Amigo's present address: Departamento de Bioquímica, Instituto de Química, Universidade de, São Paulo, 13560-970 São Paulo, Brazil.

DOI:10.1523/JNEUROSCI.2702-14.2015

Copyright $\odot 2015$ the authors $\quad 0270-6474 / 15 / 353566-16 \$ 15.00 / 0$ death through persistent activation of NMDA receptors (Tymianski et al., 1993; Budd and Nicholls, 1996; Nicholls, 2008).

Mitochondrial $\mathrm{Ca}^{2+}$ plays a key role in glutamate excitotoxicity and preventing $\mathrm{Ca}^{2+}$ uptake by mitochondria protects against neuronal death (Stout et al., 1998; Qiu et al., 2013). Another important player is poly(ADP ribose) polymerase-1 (PARP-1), activated by DNA strand breaks, which uses $\mathrm{NAD}^{+}$to produce ADP-ribose polymers bound to proteins (Andrabi et al., 2006). Glutamate excitotoxicity causes the production of reactive oxygen species (ROS) and reactive nitrogen species (BrennanMinnella et al., 2013), which damage DNA and activate PARP-1, and neurons treated with PARP-1 inhibitors (Abramov and Duchen, 2008; Duchen, 2012) and PARP-1 KO mice are remarkably resistant to glutamate/NMDA excitotoxicity (Eliasson et al., 1997; Mandir et al., 2000).

The detrimental role of PARP-1 activation in excitotoxicity has been attributed to the PAR polymer (Andrabi et al., 2006), whose formation depletes cytosolic $\mathrm{NAD}^{+}$, which would lead to an impairment of the $\mathrm{NAD}^{+}$-dependent steps of glycolysis (Alano et al., 2010) or to a reduction of cytosolic ATP as a result of ATP use in the resynthesis of $\mathrm{NAD}^{+}$(Zhang et al., 1994). However, little is known of the effects of PARP-1 activation on mitochondrial $\mathrm{NAD}^{+}$and ATP levels, particularly within the time window of the immediate response to glutamate/NMDA. 
SCaMCs/APCs are mitochondrial ATP-Mg/Pi carriers (Aprille, 1993; Fiermonte et al., 2004; del Arco and Satrústegui, 2004) involved in $\mathrm{Ca}^{2+}$ stimulation of mitochondrial respiration in liver and in increasing the $\mathrm{Ca}^{2+}$ retention capacity (CRC) of mitochondria in cancer cells (Traba et al., 2012; Amigo et al., 2013). SCaMCs have $\mathrm{Ca}^{2+}$-binding motifs facing the intermembrane space, which allow their regulation by cytosolic $\mathrm{Ca}^{2+}$, and perform an electroneutral exchange of ATP- $\mathrm{Mg}^{2-}$ or HADP ${ }^{2-}$ for $\mathrm{HPO}_{4}^{2-}$, resulting in changes in the total adenine nucleotide (AdN) concentration (ATP plus ADP plus AMP) in the mitochondrial matrix (Nosek et al., 1990). SCaMC-3/APC2/Slc25a23 expressed in liver and brain, and it is activated to half maximal levels at $\sim 3.3 \mu \mathrm{M} \mathrm{Ca}$ (Amigo et al., 2013).

The aim of the present study was to investigate the relevance of SCaMC-3 in the function of brain mitochondria and intact neurons during the early response to glutamate or NMDA through the use of SCaMC-3 KO mice (Amigo et al., 2013), particularly in the early NMDA-induced activation of respiration (Jekabsons and Nicholls, 2004; Gleichmann et al., 2009), and its impact on the delayed responses to these agonists both in vitro and in vivo. The results reveal that NMDA-induced PARP-1 activation results in a rapid drop in mitochondrial ATP levels, which is unmasked by SCaMC-3 deficiency. This drop is prevented by SCaMC-3 activity transporting AdNs into neuronal mitochondria immediately after NMDA exposure. In addition to this early effect, the increase in matrix AdNs brought about by SCaMC-3 confers a higher $\mathrm{Ca}^{2+}$ retention capacity to mitochondria, delays $\mathrm{Ca}^{2+}$ deregulation in neurons exposed to glutamate, and results in protection by SCaMC-3 against glutamate excitotoxicity in vitro and in vivo.

\section{Materials and Methods}

Animals. SCaMC-3-deficient mice were generated by Lexicon with a mixed C57BL/6Sv129 genetic background. Animals are born in Mendelian proportions and show no evident phenotypic traits. Genotyping was performed as previously described (Amigo et al., 2013). Animals were killed by cervical dislocation. All animal work performed in this study was performed in accordance with procedures approved in Directive 86/609/EEC of the European Union and with approval of the Ethics Committee of the Universidad Autónoma de Madrid.

Cortical neuron cultures and glutamate treatment. Cultures were prepared as described previously (Pardo et al., 2006). Cells were seeded at a density of $1 \times 10^{5}$ cells $/ \mathrm{cm}^{2}$ on poly-L-lysine and laminin $(1 \mu \mathrm{g} / \mathrm{ml})$ coated plates, unless otherwise indicated. Glu and NMDA treatments were performed in neuronal cultures at $8-10 \mathrm{~d}$ in vitro (DIV) to allow the expression of glutamate receptors in neurons. Medium was replaced with $600 \mu \mathrm{l}$ of MEM supplemented with the indicated NMDA/Glu concentration, making duplicates or triplicates of every concentration. After 5 min, MEM was replaced with Neurobasal medium supplemented with $\mathrm{B}-27$, GlutaMAX, and antibiotics (NBc). In experiments using PARP-1 inhibitors, these were present during preincubation, glutamate/NMDA exposure, and the recovery period in NBc. Viability assays were performed 6-24 h later with the calcein-AM versus propidium iodide method. Neuron cultures were incubated 15 min with $1 \mu \mathrm{M}$ calcein- $2 \mu \mathrm{M}$ propidium iodide (PI) in the dark, and images (five per condition) were then obtained with an Axiovert 200 epifluorescence microscope (Zeiss) coupled to a monochrome-color CCD camera using a $10 \times$ dry objective in red and green channels. Red (PI positive) and green (calcein positive) cells were counted in 11 fields per treatment, and genotypes and a live/total cells percentage were generated and compared between genotypes.

Imaging of cytosolic-mitochondrial $\mathrm{Ca}^{2+}$ and ATP in primary neuronal cultures. Single-cell measurements of cytosolic and mitochondrial $\mathrm{Ca}^{2+}$ were performed as described previously (Llorente-Folch et al., 2013) using neurons loaded with Fura-2, or neurons transfected using Effectene (Qiagen) $24 \mathrm{~h}$ prior to the experiments either with the plasmid coding for mitochondrially targeted ratiometric GEM-GECO-1 (plasmid
32461, Addgene; Zhao et al., 2011) or with the plasmid coding for either Cyt GO-ATeam 1 or Mit GO-ATeam 2 (provided by H. Noji) and processed as previously described (Nakano et al., 2011). Experiments were performed in HEPES-control salt solution (HCSS) containing $2.5 \mathrm{~mm}$ glucose either with $2 \mathrm{mM} \mathrm{CaCl}_{2}$ or $100 \mu \mathrm{M}$ EGTA. When used, PARP-1 inhibitors were preincubated ( $24 \mathrm{~h}$ for PJ-34 and DPQ, and $10 \mathrm{~min}$ for $3-\mathrm{AB}$ ) and maintained throughout the experiment. Briefly, cells were excited for $100 \mathrm{~ms}$ at $436 / 20 \mathrm{~nm}$ for Mit-GEM-GECO1, at 485/27 nm for GO-ATeam and alternatively at 426/44 (Venus) and 472/499 (GFP) for Perceval HR measurements. The emitted fluorescence was collected through a dual-pass dichroic CFP-YFP (440/500 nm and 510/600 nm) alternatively at $480 / 40 \mathrm{~nm}$ (CFP) and 535/30 nm (YFP) for Mit-GEMGECO-1, through a FF495-Di03 dichroic at 520/35 nm (GFP) and $567 / 15 \mathrm{~nm}$ (OFP) for GO-ATeam, and at 520/35 nm (GFP) for Perceval HR probe. Images were collected every $5 \mathrm{~s}$. using a filter wheel (Lambda 10-2, Sutter Instruments; all filters purchased from Chroma) and recorded by a Hamamatsu C9100-02 camera mounted on an Axiovert 200M inverted microscope equipped with a 40X/1.3 Plan-Neofluar objective. The Mit-GEM-GECO1 emission ratio was CFP/YFP, while the GO-ATeam emission ratio was OFP/GFP, reflecting mitochondrial $\mathrm{Ca}^{2+}$ and ATP levels respectively. For Mit-GEM GECO1 imaging, ROIs were selected on mitochondrial-containing areas (identified based on their morphology). Single-cell fluorescence recordings were analyzed using Image (NIH) or MetaMorph (Universal Imaging), and data analysis was performed with Origin software (Originlab). For rescue experiments, the whole full-length cDNA sequence of SCaMC-3 was cloned into the $p C A G G S$ expression vector under the control of the $\beta$-globin promoter. $p$ CAGGS-SCaMC-3 and Mit GO-ATeam 2 were cotransfected, and experiments were performed $24 \mathrm{~h}$ later. SCaMC- 3 expression levels were assessed by immunofluorescence using a monoclonal antibody against full-length SCaMC-3, which was produced in our laboratory $(1: 100)$.

Mitochondrial and cytosolic reactive oxygen species formation. Neurons were seeded in 96-well plates at a density of $300,000 \mathrm{cells} / \mathrm{cm}^{2}$, and at 8-10 DIV were loaded with either $1 \mu \mathrm{M}$ dihydroethidium, keeping the dye present throughout measurements of cytosolic ROS; or with $3 \mu \mathrm{M}$ MitoSOX for 10 min; washed; and used to monitor mitochondrial ROS (Robinson et al., 2008). Loading and recordings were made in HCSS plus $2 \mathrm{~mm} \mathrm{CaCl}_{2}$. Hydroxyethidium and oxidized MitoSOX fluorescence was evaluated in a FLUOstar OPTIMA fluorescence plate reader using an excitation 530-10 filter and emission 620-10 BP filter, and NMDA additions were made using a fluidic controller. In addition, neurons were loaded and visualized under the microscope stage to ensure proper cytosolic and mitochondrial localization of the dyes in these loading conditions. Data analysis was performed with Origin software (Originlab).

Immunohistochemistry. Free-floating brain sections from kainic acid (KA)-treated mice were washed in PBS and blocked in PBS-1\% horse serum- $0.25 \%$ Triton $\mathrm{X}-100$ for $1 \mathrm{~h}$ before incubating overnight with the primary antibody $(1: 200$; GFAP, Dako $)$ in the same medium at $4^{\circ} \mathrm{C}$. The excess of antibody was washed three times in PBS, and a secondary fluorescent antibody (1:250; Alexa Fluor 488 anti-rabbit, Invitrogen) was then incubated for $1 \mathrm{~h}$. Secondary antibody was washed three times in PBS, and sections were mounted in polylysine-coated glass slides (Menzel-Glässer) using mowiol. Immunoreactivity was quantified using images of three different coronal sections of the hippocampus, corresponding approximately to positions 261,281 , and 301 from the Allen Brain Mouse Atlas, which were taken at $10 \times$ magnification with an Axioskop 2 Plus vertical microscope (Zeiss) coupled to a Coolsnap FX CCD camera (Roper Scientific) using the same settings for all the samples. GFAP fluorescence was quantified using ImageJ software. A region of interest including CA1, CA2, CA3, and the dentate gyrus was delimited, and its total area was calculated. The total area occupied by GFAP fluorescence was quantified by manually introducing a threshold that was maintained throughout the analysis of all images. Measures were performed in a blind manner and expressed as the percentage of the GFAP fluorescent area with respect to the total area (Zamanian et al., 2012).

Measurement of cellular oxygen consumption. The oxygen consumption rate (OCR) was measured using a Seahorse XF24 Extracellular Flux Analyzer (Seahorse Bioscience; Qian and Van Houten, 2010). Cortical pri- 
mary neurons were plated at $1.5 \times 10^{5}$ cells/well in XF24 V7 plates and incubated at $37^{\circ} \mathrm{C}$ in $5 \% \mathrm{CO}_{2}$ in the conventional serum-free $\mathrm{B} 27$ supplemented Neurobasal medium with $30 \mathrm{~mm}$ glucose (Brewer et al., 1993). Cells were equilibrated with bicarbonate-free DMEM (without pyruvate, lactate, glucose, glutamine, and $\mathrm{Ca}^{2+}$ ) supplemented with 2.5 mM glucose and $2 \mathrm{mM} \mathrm{CaCl}_{2}$ or $100 \mu \mathrm{M}$ EGTA for conditions of plus or minus $\mathrm{Ca}^{2+}$, for $1 \mathrm{~h}$ immediately before the assay. When used, PARP-1 inhibitors were preincubated ( $24 \mathrm{~h}$ for PJ-34 and DPQ, and $10 \mathrm{~min}$ for $3-\mathrm{AB}$ ) and maintained throughout the experiment. After a baseline measurement, neurons were stimulated with NMDA, and mitochondrial function was determined as described previously (Llorente-Folch et al., 2013). It should be noted that the differential response to 25,50 , and 100 $\mu \mathrm{M}$ NMDA is only observed within a small time window in cultured neurons, as neuronal maturation and the response to NMDA are exquisitely sensitive to the age of the culture (Abramov and Duchen, 2010; Guo et al., 2013).

Swelling and $\mathrm{Ca}^{2+}$ uptake in isolated mitochondria. Liver and brain mitochondria were isolated as previously described (Contreras and Satrústegui, 2009) and resuspended in MSK buffer (75 mM D-mannitol,

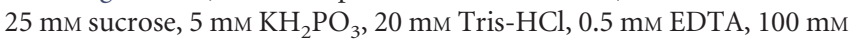
$\mathrm{KCl}$, and $0.1 \% \mathrm{BSA}$ free of fatty acids, $\mathrm{pH} 7.4$ ). All experiments were performed in MSK devoid of EDTA at $30^{\circ} \mathrm{C}$ in the presence of $1 \mathrm{~mm}$ $\mathrm{MgCl}_{2}$ and respiratory substrates (5 mM succinate plus $2 \mu \mathrm{M}$ rotenone), and in the presence or absence of AdNs (ATP or ADP). Mitochondrial swelling in liver mitochondria was measured by monitoring the decrease in absorbance of the suspension at $540 \mathrm{~nm}$, reflecting decreased light scattering, as previously described (Amigo et al., 2012), using a Nicolet Evolution 300 spectrophotometer (Thermo Scientific) provided with temperature control and continuous stirring. Swelling was monitored through sequential additions of $200-1000 \mathrm{nmol} \mathrm{CaCl}_{2}$. Forty micrograms of alamethicin was added at the end of the assays as a control for maximal swelling. The CRC of isolated brain mitochondria was measured with the $\mathrm{Ca}^{2+}$-sensitive fluorescent probe Calcium-Green $5 \mathrm{~N}(0.1$ $\mu \mathrm{M}$; excitation, $506 \mathrm{~nm}$; emission, $532 \mathrm{~nm}$ ) as previously described (Traba et al., 2012), using an AMINCO-Bowman fluorimeter provided with continuous stirring and temperature control. One hundred micromolar digitonin was added to the buffer. After 3-5 min of incubation, mitochondria were challenged with subsequent $10-20 \mathrm{nmol} \mathrm{CaCl}_{2}$ additions, as indicated in the figure legends, and $\mathrm{Ca}^{2+}$ uptake into mitochondria was measured from the decrease in external $\mathrm{Ca}^{2+}$ reflected in decreased calcium-green fluorescence.

Kainic acid treatment. KA ( $25 \mathrm{mg} / \mathrm{kg}$; Sigma-Aldrich) was administrated intraperitoneally to 3-month-old male wild-type (WT) and SCaMC-3 KO mice ( $n=8$ mice for each genotype). In each experiment, wild-type and SCaMC-3 KO mice from the same litter were visually monitored in parallel for $2 \mathrm{~h}$, and seizure severity was quantified in a blind manner using the following classification (McLin et al., 2006): (1) unmoving and crouched in a corner, staring; (2) body stretched out, tail becomes straight and rigid, ears laid back, with bulging eyes; (3) repetitive head bobbing, rears into a sitting position; (4) rearing and falling, tonic clonic seizures broken by periods of total stillness, jumping clonus, running clonus; (5) continuous level 4 seizures; (6) body in clonus, no longer using limbs to maintain posture, usually precursor to death; and (7) death. For data analysis, the most severe state every 5 min was used. Mice were killed $7 \mathrm{~d}$ after drug administration, and brain sections extracted for histological analysis as described above.

Electrophysiology. Whole-cell current-clamp recordings were obtained from in vitro cultured neurons at 8-9 DIV. Patch pipettes (3-6 M $\Omega$ ) were filled with an intracellular solution containing $115 \mathrm{mM} \mathrm{K}$-gluconate, $20 \mathrm{~mm} \mathrm{KCl}, 2 \mathrm{~mm} \mathrm{MgCl}_{2}$, $10 \mathrm{~mm}$ HEPES, $4 \mathrm{~mm} \mathrm{ATP} \cdot 2 \mathrm{Na}$, and $0.3 \mathrm{~mm}$ $\mathrm{GTP} \cdot 3 \mathrm{Na}$, adjusted to $\mathrm{pH} 7.2$ with $\mathrm{KOH}$, and to $290 \mathrm{mOsm}$ with $\mathrm{KCl}$. During recording, neurons were perfused with artificial CSF containing $119 \mathrm{~mm} \mathrm{NaCl}, 2.5 \mathrm{~mm} \mathrm{KCl}, 1 \mathrm{~mm} \mathrm{NaH} \mathrm{PO}_{4}, 11 \mathrm{~mm}$ glucose, $26 \mathrm{~mm}$ $\mathrm{NaHCO}_{3}, 1.3 \mathrm{~mm} \mathrm{MgCl}_{2}$, and $2.5 \mathrm{mM} \mathrm{CaCl}_{2}$, and gassed with $95 \% \mathrm{O}_{2}, 5 \%$ $\mathrm{CO}_{2}$. Current-clamp whole-cell recordings were obtained with a Multiclamp 700A amplifier (Molecular Devices). All properties were analyzed using pCLAMP Clampfit version 10.3 (Molecular Devices). Excitability was quantified as the number of action potentials (APs) evoked by a series of depolarizing current steps $(0-400$ pA, $350 \mathrm{~ms})$. Resting mem- brane potential, threshold for action potential firing, and input resistance were obtained from the same traces.

Statistical analysis. In all cases, data are presented as the mean \pm SEM. The number of independent experiments is indicated in the figure legend in each case. Statistical significance was determined using a two-tailed unpaired Student's $t$ test, unless otherwise indicated.

\section{Results}

The early stimulation of respiration in response to NMDA is highly $\mathrm{Ca}^{2+}$ sensitive and is larger in WT than in SCaMC-3 KO neurons

$\mathrm{Ca}^{2+}$-dependent AdN uptake through the ATP-Mg/Pi carrier increases respiration in AdN-depleted mitochondria (Nosek et al., 1990; Amigo et al., 2013), and is responsible for the acute increase in matrix AdN content and coupled respiration caused by glucagon in the liver (Aprille et al., 1982; Amigo et al., 2013). Neurons have a large capacity to increase mitochondrial coupled respiration in response to high workloads, which depends on $\mathrm{Ca}^{2+}$ activation of respiration, rather than on $\mathrm{Ca}^{2+}$-induced ATP utilization (Llorente-Folch et al., 2013).

To test the effects of SCaMC-3 in this context, we studied the role of SCaMC-3 in respiration of intact neurons during an increase in workload caused by exposure to NMDA. NMDA causes $\mathrm{Na}^{+}$and $\mathrm{Ca}^{2+}$ entry through ionotropic NMDA receptors and voltage-gated $\mathrm{Ca}^{2+}$ channels in cortical neurons. The absence of $\mathrm{Ca}^{2+}$, which prevents the increase in $\left[\mathrm{Ca}^{2+}\right]_{\mathrm{i}}$ (Fig. $1 B$ ) causes a larger increase in $\mathrm{Na}^{+}$(Fig. $1 A$ ), possibly because of competition between $\mathrm{Na}^{+}$and $\mathrm{Ca}^{2+}$, as both cations are permeable through NMDA receptors (Mayer and Westbrook, 1987). Most of the workload caused by the entry of these cations is due to $\mathrm{Na}^{+}$entry rather than $\mathrm{Ca}^{2+}$ entry, which triggers $\mathrm{Na}^{+}$efflux on the $\mathrm{Na}^{+}$ pump (Attwell and Laughlin, 2001; Llorente-Folch et al., 2013). However, NMDA induced an increase in OCR that was much larger in the presence of than in the absence of $\mathrm{Ca}^{2+}$ (Fig. 1C,D), even when the $\mathrm{Na}^{+}$-dependent workload is higher in $\mathrm{Ca}^{2+}$-free medium. This suggests that the lack of $\mathrm{Ca}^{2+}$ regulation of mitochondrial respiration limits NMDA-induced stimulation of respiration in a $\mathrm{Ca}^{2+}$-free medium. In fact, cytosolic ATP imaging with the low-affinity ATP probe Cyt GO-ATeam $1\left(K_{\mathrm{d}}=7.1\right.$ $\mathrm{mM}$ ), which is not affected by physiological $\mathrm{pH}$ changes (Nakano et al., 2011), showed that NMDA promotes a much larger depletion of cytosolic ATP in the absence of $\mathrm{Ca}^{2+}$ than in its presence (Fig. 1E). This indicates that during NMDA exposure in $\mathrm{Ca}^{2+}$ free medium, failure to upregulate mitochondrial respiration in response to $\mathrm{Ca}^{2+}$ causes a progressive fall in cytosolic ATP.

NMDA-induced early mitochondrial depolarization, shown as a decrease in tetramethylrhodamine methyl ester (TMRM) fluorescence (Davidson et al., 2007), was partially prevented in the absence of $\mathrm{Ca}^{2+}$ (Fig. $1 F$ ), and completely prevented in the presence of oligomycin (Fig. $1 G$ ). Moreover, when NMDA was added in the presence of $\mathrm{Ca}^{2+}$ and oligomycin, an increase in TMRM fluorescence was observed (Fig. $1 G$ ), indicating mitochondrial hyperpolarization consistent with NMDA-induced $\mathrm{Ca}^{2+}$ stimulation of mitochondrial energization that is unmasked when ATP synthesis is prevented by oligomycin.

SCaMC-3 is widely expressed in brain, and is present in primary cortical neurons and, at lower levels, in glial cultures. Brain mitochondria from SCaMC-3 KO mice do not show changes in respiration with complex I and II substrates, in cytochrome oxidase activity, or in the content of adenine nucleotides (results not shown). We investigated early respiratory responses to NMDA in WT and SCaMC-3 KO neurons both in the presence and absence of $\mathrm{Ca}^{2+}$ (Fig. 2A-C). Neurons from both genotypes showed a 
A $\quad 100 \mu \mathrm{M}$ NMDA Oua/Mon

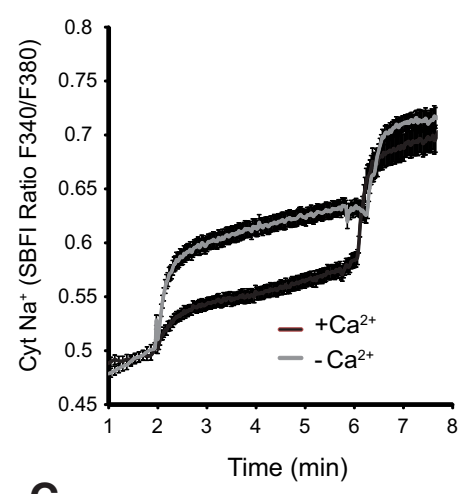

C

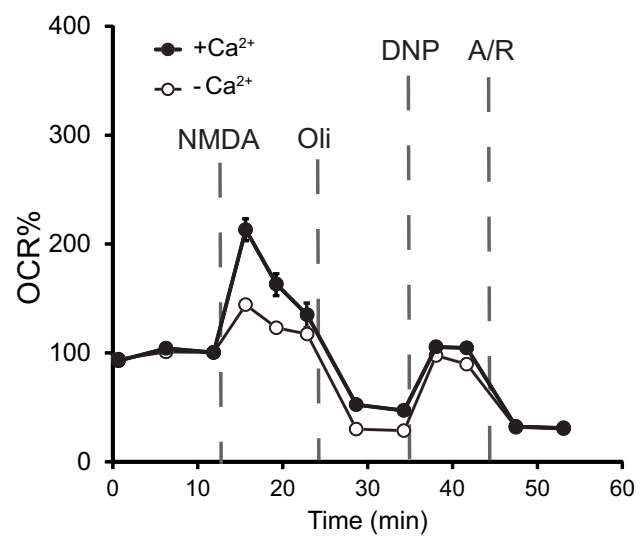

E

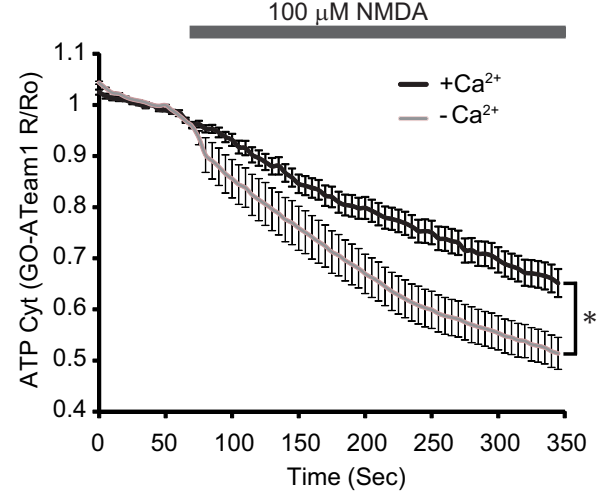

B

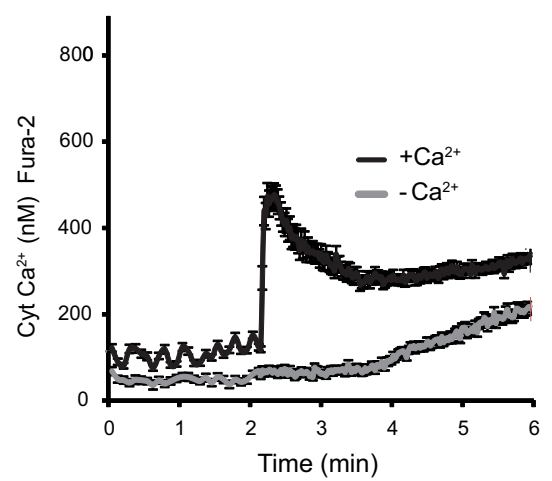

D
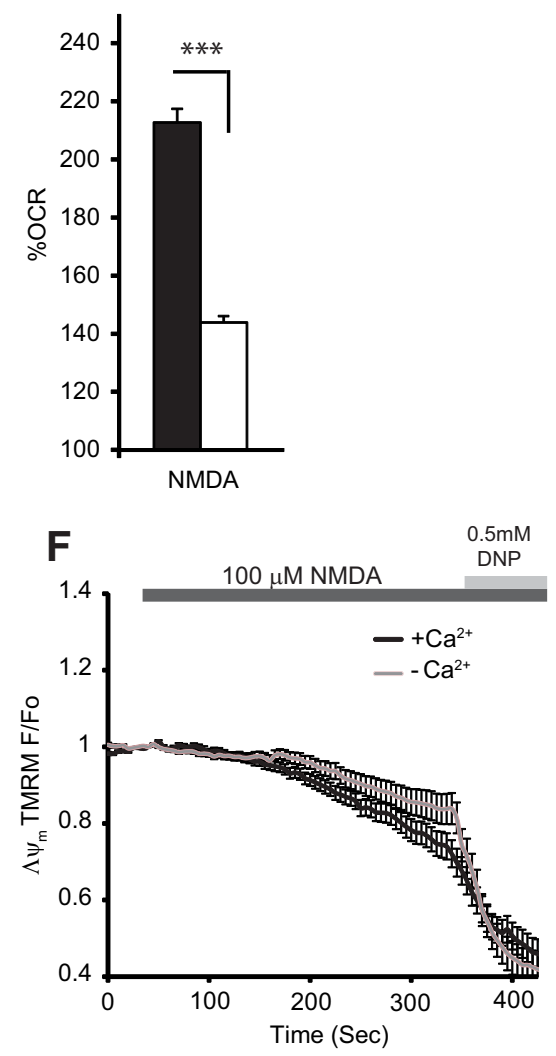

G

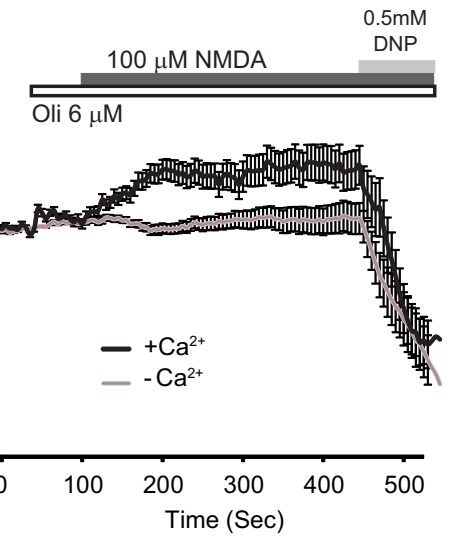

Figure 1. NMDA-induced response in cortical neurons. $\boldsymbol{A}-\boldsymbol{G}$, Changes in $\left[\mathrm{Na}^{+}\right]_{\mathrm{i}}(\boldsymbol{A}),\left[\mathrm{Ca}^{2+}\right]_{\mathrm{i}}(\boldsymbol{B}), 0 \mathrm{CR}(\boldsymbol{C}, \boldsymbol{D}),[\mathrm{ATP}]_{\mathrm{cyt}}(\boldsymbol{E})$, and mitochondrial membrane potential $(\Delta \psi ; \boldsymbol{F}, \boldsymbol{G})$ in cortical neurons stimulated with $100 \mu \mathrm{m} \mathrm{NMDA}$ in the presence of $2 \mathrm{~mm} \mathrm{Ca}^{2+}$ or in a $\mathrm{Ca}^{2+}$-free medium $\left(100 \mu \mathrm{m} \mathrm{EGTA)} . \boldsymbol{A},\left[\mathrm{Na}^{+}\right]_{\mathrm{i}}\right.$ in sodium-binding benzofuran isophthalate (SBFI)-loaded neurons $(\sim 90$ neurons per condition and 3 independent platings). Ouabain (0ua; $0.1 \mu \mathrm{M}$ ) and monensin (Mon; $10 \mathrm{mM}$ ) were added for equilibration of extra- and intracellular [ $\mathrm{Na}^{+}$] at the end of the experiments. $\boldsymbol{B}$, $\left[\mathrm{Ca}^{2+}\right]_{\text {cyt }}$ in Fura-2 loaded neurons ( $~ 60$ neurons per condition and 2 independent platings). $\boldsymbol{C}, \boldsymbol{D}, \mathrm{NMDA}$-induced stimulation of OCR as a percentage of basal values ( $n=7-9$ experiments). $\boldsymbol{E}$, $[A T P]_{\text {cyt }}$ in neurons transfected with cyt-G0-ATeam1; results were expressed as R/Ro for normalization to prestimulation values (Ro); results were normalized to prestimulation values and correspond to $30-50$ neurons per condition and independent platings. The drop of ATP values with respect to basal levels $300 \mathrm{~s}$ after NMDA addition was $34.85 \pm 2.7 \%$ in the presence of $\mathrm{Ca}{ }^{2+}$ and $48.60 \pm 3.1 \%$ in the absence of $\mathrm{Ca}^{2+} . \boldsymbol{F}, \boldsymbol{G}$, Neurons were loaded with $5 \mathrm{nM}$ TMRM (nonquench mode), and were allowed to equilibrate for 30 min before NMDA addition $(\boldsymbol{F})$ or after a pretreatment with $6 \mu \mathrm{m}$ oligomycin (Oli) before NMDA addition (G). Results (mean \pm SEM) were normalized to prestimulation values. Dinitrophenol (DNP) and antimycin/rotenone (A/R; $1 \mu \mathrm{M} / 1 \mu \mathrm{M})$ were added at the end of experiments to ensure complete mitochondrial depolarization. ${ }^{*} p \leq 0.05 ; * *{ }^{* *} \leq 0.001$, two-tailed unpaired Student's $t$ test.

similar OCR response to NMDA in $\mathrm{Ca}^{2+}$-free medium, while the increased response in the presence of $\mathrm{Ca}^{2+}$ that is characteristic of WT neurons was severely reduced in $\mathrm{KO}$ neurons (Fig. 2C), although the initial increase in $\left[\mathrm{Ca}^{2+}\right]_{\mathrm{i}}$ was the same in neurons from both genotypes (Fig. 2D).

Figure $2 E-G$ shows that in $\mathrm{Ca}^{2+}$-free medium, NMDA caused a similar drop in cytosolic ATP in WT and SCaMC-3 KO neurons; however, in the presence of $\mathrm{Ca}^{2+}$, ATP depletion was larger in $\mathrm{KO}$ neurons than in WT neurons (Fig. 2E-G). This was confirmed using the ATP-to-ADP sensor Perceval HR (Tantama et al., 2013), which showed a larger fall in the ATP/ADP ratio after NMDA exposure in SCaMC-3 KO neurons than in WT neurons (Fig. $2 \mathrm{H}-\mathrm{J}$ ). These results suggest that failure to upregulate respiration in response to NMDA in the presence of $\mathrm{Ca}^{2+}$ caused the larger fall in cytosolic ATP/ADP ratio in KO neurons.

We next determined matrix-free $\mathrm{Ca}^{2+}$ levels in SCaMC-3deficient neurons exposed to NMDA with the mitochondrially 

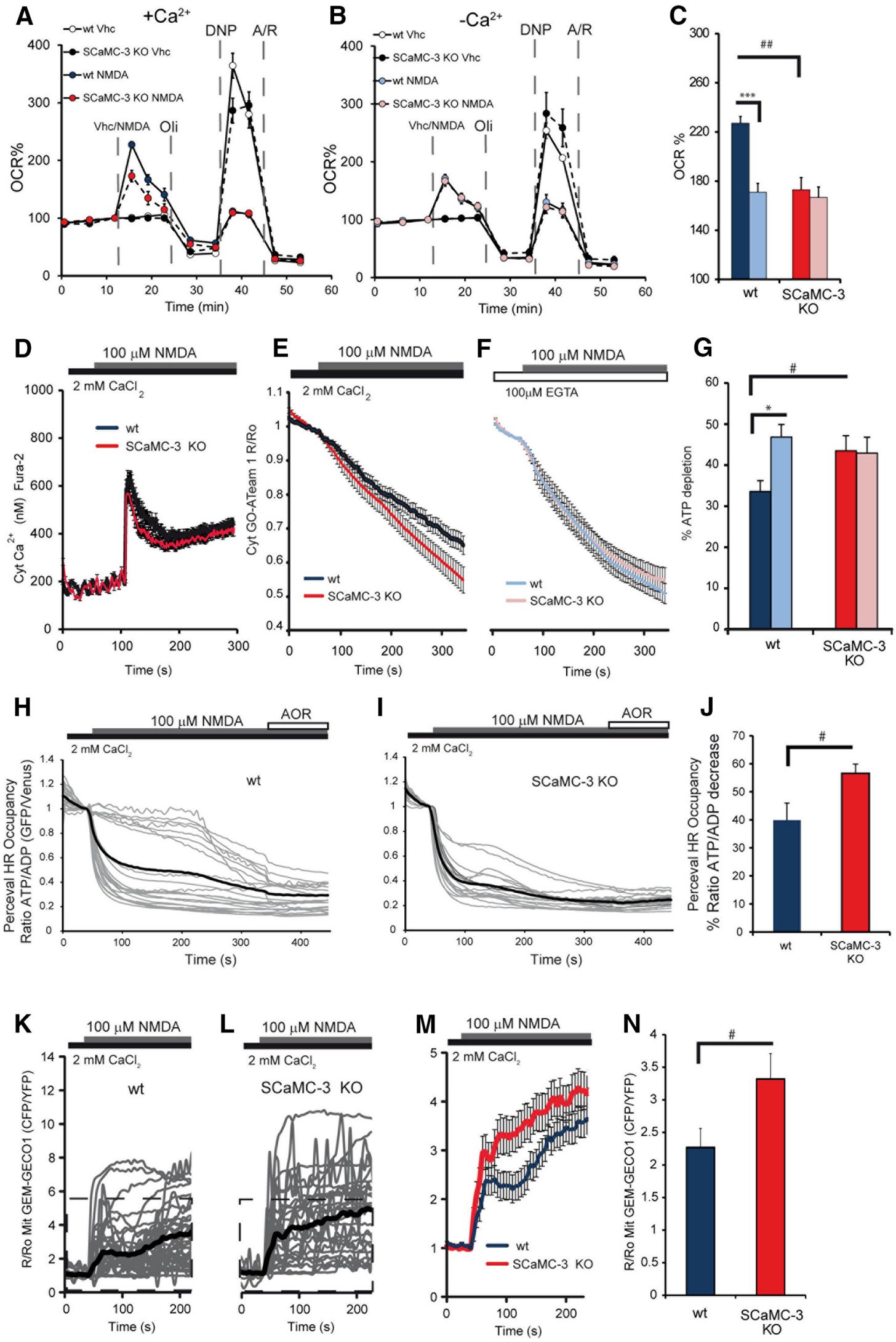

Figure 2. SCaMC-3-deficient neurons show decreased respiratory stimulation, and higher mitochondrial $\mathrm{Ca}^{2+}$ and larger cytosolic ATP depletion upon NMDA exposure: $A, B, N M D A$ induced the stimulation of OCR in cortical neurons in $2 \mathrm{~mm} \mathrm{Ca}{ }^{2+}$ medium $(\boldsymbol{A})$ or $\mathrm{Ca}^{2+}$-free medium (B; $100 \mu \mathrm{m}$ EGTA). $\boldsymbol{C}$, Stimulation of respiration (as a percentage of basal values) in experiments is shown in $\boldsymbol{A}$ and $\boldsymbol{B}\left(n=10-12\right.$ experiments). $\boldsymbol{D}$, Changes in $\left[\mathrm{Ca}^{2+}\right]_{\text {cyt }}$ in Fura-2-loaded neurons obtained by stimulation with $100 \mu \mathrm{m} \mathrm{NMDA}$ in WT (blue trace) or SCaMC $-3 \mathrm{KO}$ (red trace) neurons; data are presented as the mean \pm SEM of at least 60 neurons, and two different platings are shown. $E, F,[A T P]_{\text {cyt }}$ in neurons transfected with cyt-G0-ATeam1 stimulated with $100 \mu \mathrm{M}$ NMDA under the mentioned conditions. G, Quantification of ATP depletion $300 \mathrm{~s}$ after NMDA. Data from at least 30 neurons and independent platings, normalized to (Figure legend continues.) 
targeted, ratiometric GEM-GECO1 (Zhao et al., 2011). In response to NMDA, there was an initial steep increase in Mit-GEM/ GECO1 ratio $\left(\left[\mathrm{Ca}^{2+}\right]_{\text {mit }}\right.$ ) followed by a secondary rise (Fig. $2 \mathrm{~K}-$ $N)$, similar to those reported in response to lower $(10-20 \mu \mathrm{M})$ NMDA doses with other protein-based $\mathrm{Ca}^{2+}$ sensors expressed in neuronal mitochondria (Qiu et al., 2013). The initial increase was greater in SCaMC-3 KO neurons than in WT neurons, and SCaMC-3-deficient neurons also maintained a higher $\left[\mathrm{Ca}^{2+}\right]_{\mathrm{mit}}$ level throughout the duration of the recordings (Fig. 2M), thus ruling out impaired signaling to mitochondria via the $\mathrm{Ca}^{2+}$ uniporter as a cause of the blunted NMDA stimulation of OCR in SCaMC-3 KO neurons. NMDA-induced depolarization was similar in WT and KO neurons (results not shown), excluding differences in mitochondrial depolarization as the cause of the reduced OCR stimulation.

\section{NMDA exposure causes a rapid drop in mitochondrial ATP,} which is prevented by AdN uptake through SCaMC-3

Having found that the deficient respiratory response to NMDA in SCaMC-3 KO neurons is not caused by a lower ATP demand but reflects a failure to upregulate respiration in the presence of $\mathrm{Ca}^{2+}$, we next studied mitochondrial ATP levels after NMDA exposure both in the presence and in the absence of $\mathrm{Ca}^{2+}$. To this end, we used the high-affinity ATP probe Mit GO-ATeam $2\left(K_{d}\right.$ $=2.3 \mathrm{~mm}$; Nakano et al., 2011) and imaged mitochondrial ATP changes caused by NMDA [Fig. 3A-D (images from a representative experiment in $D)$ ]. In the presence of $2 \mathrm{mM} \mathrm{CaCl}_{2}, \mathrm{NMDA}$ was found to promote a delayed drop in mitochondrial ATP levels in control neurons (Fig. $3 A, D$ ). Strikingly, SCaMC-3 KO neurons showed an immediate steep fall in $[\mathrm{ATP}]_{\text {mit }}$. Differences among genotypes disappeared in $\mathrm{Ca}^{2+}$-free medium (Fig. $3 B$ ). The expression of SCaMC-3 in the KO neurons with $p C A G G S$ SCaMC-3 resulted in prevention of the fall in mitochondrial ATP caused by NMDA (Fig. 3 E, F). Under these conditions, SCaMC-3 protein levels were restored, as verified by immunofluorescence (Fig. 3G). These results suggest an important role of SCaMC-3 in the maintenance of ATP homeostasis in the early response to NMDA exposure. In the absence of SCaMC-3, NMDA causes an immediate drop in $[\mathrm{ATP}]_{\text {mit }}$ levels and also, though less pronounced, in cytosolic ATP.

Our results indicate that a drop in $[\mathrm{ATP}]_{\text {mit }}$ is prevented through $\left[\mathrm{Ca}^{2+}\right]_{\mathrm{i}}$-stimulated import of nucleotides from the cytosol to the mitochondria across SCaMC-3. This mitochondrial carrier transports both ATP- $\mathrm{Mg}^{2-}$ and monoprotonated ADP $\left(\mathrm{HADP}^{2-}\right)$, the affinity for ATP- $\mathrm{Mg}^{2-}$ is greater than for HADP $^{2-}$ (Fiermonte et al., 2004), and brain ATP levels are several fold higher than those of ADP (Hattori et al., 2010). On the other hand, NMDA and glutamate induce a rapid drop in the ATP/ADP ratio in cultured neurons (Fig. $2 H-J$; Tantama et al.,

\section{$\leftarrow$}

(Figure legend continued.) prestimulation values. $\boldsymbol{H}, \boldsymbol{I}$, Cytosolic ATP/ADP ratio (Perceval HR occupancy, GFP/Venus ratio fluorescence) was measured in WT $(\boldsymbol{H})$ or SCaMC-3 KO neurons $(\boldsymbol{I})$ $24 \mathrm{~h}$ after Perceval HR transfection, and stimulated with $100 \mu \mathrm{M}$ NMDA in $2 \mathrm{~mm} \mathrm{Ca}^{2+}$ medium. $J$, Quantification of the different parameters $40 \mathrm{~s}$ after NMDA is shown. Antimycin-oligomycinrotenone (AOR) was added at the time indicated. Data from at least 20 neurons and independent platings. $\boldsymbol{K}-\boldsymbol{N}$, Neurons transfected with a Mit-GEM-GECO1 probe to determine changes in $\left[\mathrm{Ca}^{2+}\right]_{\text {mit }}$. Recordings from at 30 cells in $2 \mathrm{~mm} \mathrm{CaCl}$ media and 20 independent experiments were used. $\boldsymbol{K}-\boldsymbol{M}$, Individual cell recordings (in gray) and average (thick black trace) were shown for WT neurons (K), SCaMC-3 KO neurons ( $L$ ), and a comparison of mean \pm SEM values $(\boldsymbol{M}) . \boldsymbol{N}$, Results were expressed as R/Ro for normalization to prestimulation values (Ro). Increase in R/Ro with respect to basal levels $50 \mathrm{~s}$ after NMDA. Data has been normalized to prestimulation values. ${ }^{*}, \# p \leq 0.05 ; \# \# p \leq 0.01 ;{ }^{* * *} p \leq 0.001$, two-tailed unpaired Student's $t$ test.
2013), indicating that ADP levels increase upon NMDAdependent ATP breakdown, making it also a likely candidate to be transported under these conditions. To explore this possibility, we used a cytosolic $\mathrm{Mg}^{2+}$ probe, magfura, which has been used as an indicator of cytosolic ATP levels (Abramov and Duchen, 2010). NMDA addition in the presence of $\mathrm{Ca}^{2+}$ resulted in an increase in cytosolic $\mathrm{Mg}^{2+}$ concentration, which was lower in $\mathrm{KO}$ than in WT neurons (Fig. $3 \mathrm{H}, \mathrm{I}$ ). Such an increase has been taken to reflect ATP hydrolysis, which leaves $\mathrm{Mg}^{2+}$ unbound (Abramov and Duchen, 2010). However, both ATP and ADP bind $\mathrm{Mg}^{2+}$, with ATP having higher affinity than ADP (Chinopoulos et al., 2009). If cytosolic $\mathrm{Mg}^{2+}$ does not increase as much in the $\mathrm{KO}$, this would suggest that either cytosolic ATP is not depleted as much (which we have seen is not the case; Fig. 2E) or that free $\mathrm{Mg}^{2+}$ is kept low by binding to $\mathrm{HADP}^{2-}$. HADP ${ }^{2-}$ may be maintained in the cytosol to a larger extent in SCaMC-3 deficiency if $\mathrm{HADP}^{2-}$ is transported by SCaMC-3. Therefore, it appears that the most likely cargo carried by SCaMC-3 after NMDA exposure is $\mathrm{HADP}^{2-}$ rather than ATP-Mg.

\section{NMDA-induced AdN uptake in mitochondria through SCaMC-3 causes an increase in coupled respiration, which is secondary to the mitochondrial AdN drop}

We have previously observed that respiratory stimulation in intact neurons by other large $\left[\mathrm{Ca}^{2+}\right]$ signals (high $\mathrm{K}^{+}$depolarization) is not dependent on SCaMC-3 (Llorente-Folch et al., 2013), and studies in liver mitochondria have shown that SCaMC-3dependent accumulation of AdNs increases coupled respiration only in AdN-depleted mitochondria (Amigo et al., 2013). Therefore, we wondered whether the effect of SCaMC-3 on respiration was dependent on a fall in mitochondrial ATP content at the time of stimulation. This possibility was addressed by studying the responses to different doses of NMDA.

Stimulation of respiration by $25 \mu \mathrm{M}$ NMDA was slightly lower than with $50 \mu \mathrm{M}$ NMDA but was sustained, while respiratory stimulation with $50 \mu \mathrm{M}$ NMDA was not (Fig. $4 A$ ). Interestingly, the respiratory response to $25 \mu \mathrm{M}$ NMDA was the same in WT and SCaMC-3 KO neurons (Fig. 4B) with the same evoked $\left[\mathrm{Ca}^{2+}\right]_{\mathrm{i}}$ increase (Fig. $4 C$ ). Nevertheless, stimulation of AdN uptake in mitochondria by SCaMC-3 was observed at both high (Fig. 4A) and low NMDA levels, as the lack of SCaMC-3 resulted in an initial fall in $[\mathrm{ATP}]_{\text {mit }}$ content in both cases, albeit less pronounced at low NMDA levels (Fig. 4D). This suggests that SCaMC-3 is activated at both NMDA concentrations. However, respiration was increased only at high NMDA levels, where a fall in $[\mathrm{ATP}]_{\text {mit }}$ was also revealed in SCaMC-3-deficient neurons. Therefore, the effects of SCaMC-3 on respiration in response to $100 \mu \mathrm{M}$ NMDA are explained by the early $[\mathrm{ATP}]_{\text {mit }}$ depletion, which allows the effects of the nucleotides entering through SCaMC-3 to increase respiration through mass action ratio on ATP synthesis or ADP allosteric effect on Krebs cycle enzymes (Nichols et al., 1994; Glancy and Balaban, 2012).

\section{PARP-1 activation contributes to the fall in $[A T P]_{\text {mit }}$ and to the blunted stimulation of respiration in SCaMC-3 KO neurons}

We have next studied the possible causes of the NMDA-induced fall in $[\mathrm{ATP}]_{\text {mit }}$ and blunted respiratory increase in SCaMC-3 KO neurons. A NMDA-dependent $\left[\mathrm{Ca}^{2+}\right]$ increase promotes superoxide formation (Brennan et al., 2009), which, in combination with NO, has been suggested to cause damage to DNA and PARP-1 activation (Mandir et al., 2000; Duan et al., 2007; Duchen, 2012). 
A

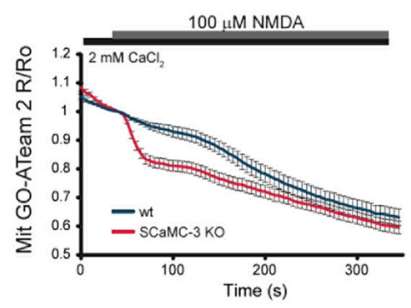

E

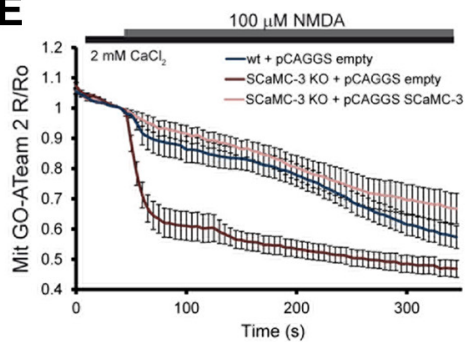

B

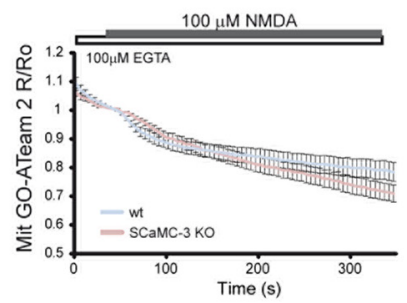

$F$
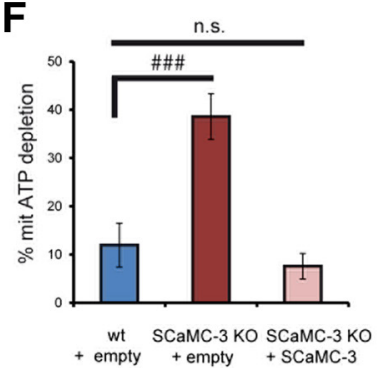

D
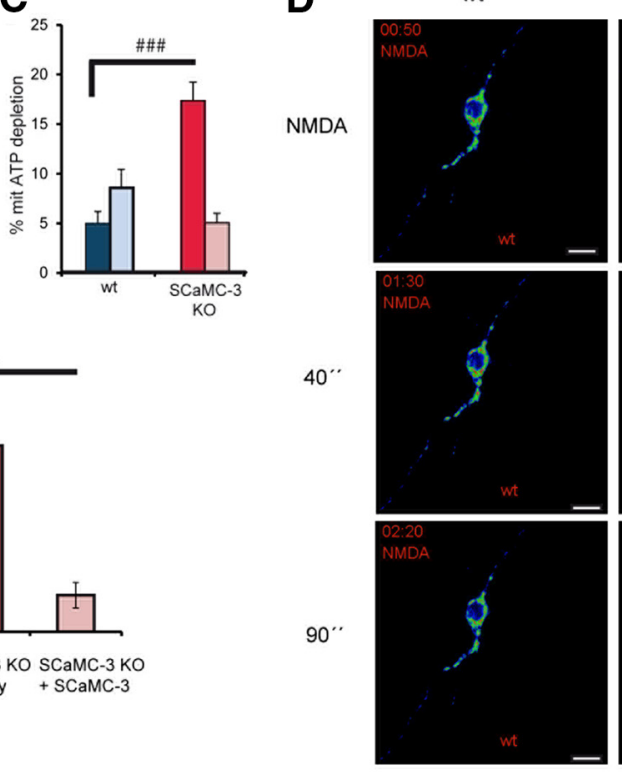

SCaMC-3 KO
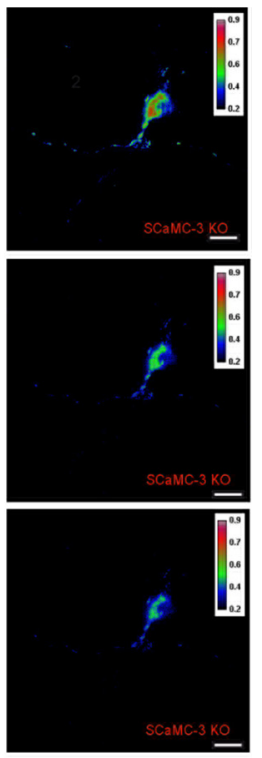

G

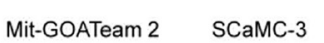

Merge
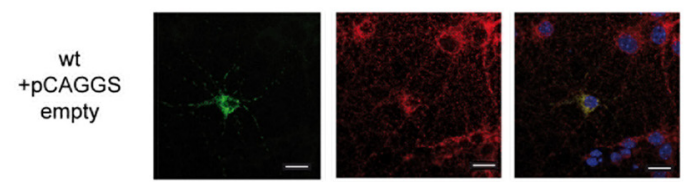

SCaMC-3 KO +pCAGGS empty
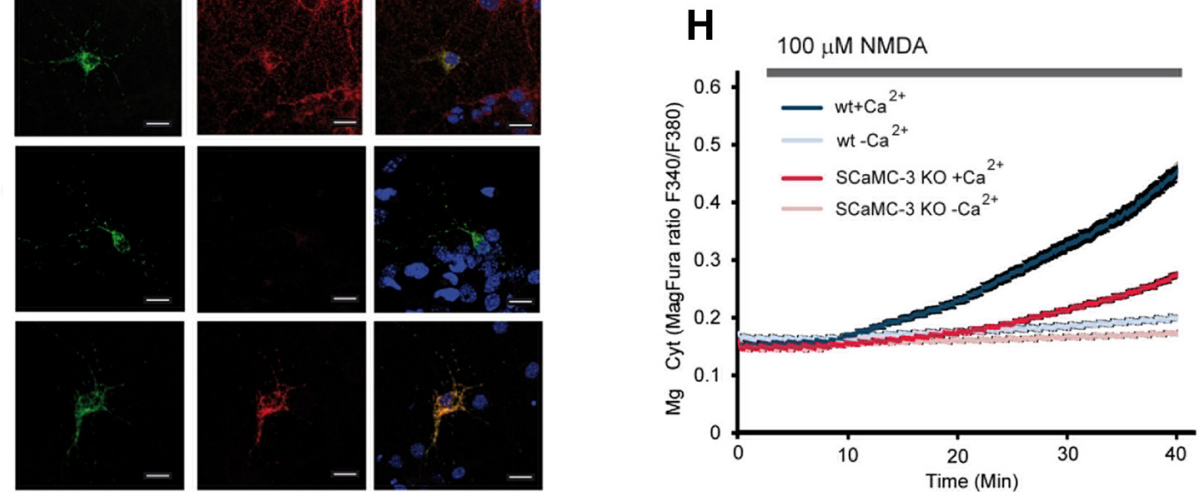

I

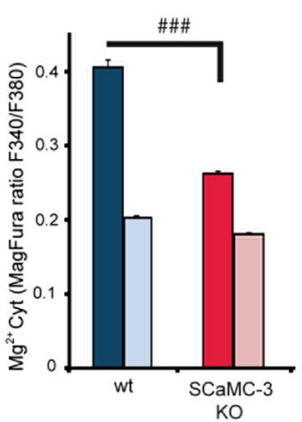

Figure 3. SCaMC-3 KO neurons show an early drop in mitochondrial ATP and a delayed increase in cytosolic $\mathrm{Mg}^{2+}$. $A, B$, Mitochondrial ATP in neurons transfected with mit-G0-ATeam2 stimulated with $100 \mu \mathrm{M} \mathrm{NMDA}$ in $2 \mathrm{~mm} \mathrm{Ca}^{2+}$ medium $(\boldsymbol{A})$ or $\mathrm{Ca}^{2+}$-free medium $(\boldsymbol{B} ; 100 \mu \mathrm{M} \text { EGTA). Data are from at least } 30 \text { neurons and independent platings. } \boldsymbol{C} \text {, Quantification of [ATP }]_{\text {mit }}$ depletion $35 \mathrm{~s}$ after NMDA. The drop in ATP values with respect to basal levels was $5.01 \pm 1.17 \%$ for WT neurons and $17.36 \pm 1.85 \%$ for SCaMC-3 KO neurons). D, Representative images of Mit-GOATeaM-2 ratio from WT and SCaMC-3 K0 neurons at 0, 40, and 90 s after NMDA exposure in $2 \mathrm{~mm} \mathrm{Ca}^{2+}$ medium. E, Mitochondrial ATP in WT neurons (blue trace; $n=10$ ) or SCaMC-3 K0 neurons (dark red trace; $n=11$ ) cotransfected with mit-G0-ATeam2 and $p$ CAGGS empty vector or SCaMC-3 KO neurons with $p$ CAGGSSCaMC-3 vector (light red trace; $n=14$ ) stimulated with 100 $\mu$ M NMDA. $F$, Quantification of $[A T P]_{\text {mit }}$ depletion $35 \mathrm{~s}$ after NMDA. G, Immunofluorescence against SCaMC-3 (red), GFP fluorescence from mit-G0-ATeam2 (green) and merging with DAPI staining nuclei (blue). $\boldsymbol{H}$, Changes in $\left[\mathrm{Mg}^{2+}\right]_{\text {cyt }}$ in magfura-2-loaded neurons obtained by stimulation with $100 \mu \mathrm{m} \mathrm{NMDA} \mathrm{in} \mathrm{WT} \mathrm{(blue} \mathrm{traces)} \mathrm{or} \mathrm{SCaMC-3} \mathrm{KO}$ (red traces) neurons in $2 \mathrm{~mm} \mathrm{Ca}{ }^{2+}$ medium (dark traces) or $\mathrm{Ca}^{2+}$-free medium (light traces). I, Mean values $30 \mathrm{~min}$ after NMDA from at least 40 neurons per condition. Data have been normalized to prestimulation values. \#\#\# $\leq 0.001$, two-tailed unpaired Student's $t$ test. Scale bars, $10 \mu \mathrm{m}$.

We wondered whether the decrease in $[\mathrm{ATP}]_{\text {mit }}$, and blunted NMDA-stimulated respiration in SCaMC-3 KO neurons could be associated with an early activation of PARP-1 through the $\mathrm{Ca}^{2+}-\mathrm{ROS}-\mathrm{PARP}-1$ pathway. Indeed, NMDAinduced 2-hydroxyethidium formation, which detects superoxide, was very low in the absence of $\mathrm{Ca}^{2+}$ in WT or $\mathrm{KO}$ neurons, but greatly increased in the presence of $\mathrm{Ca}^{2+}$ especially in the $\mathrm{KO}$ neurons (Fig. 5A,B). Moreover, NMDA-induced oxidation of MitoSOX, a mitochondrial superoxide detector (Robinson et al., 2008), was also higher in SCaMC-3 KO than WT neurons (Fig. $5 C, D$ ). PARP- 1 activation by NMDA has been detected as early as $15^{\prime}$ after NMDA treatment and has been attributed to $\mathrm{Ca}^{2+}$ entry into mitochondria (Duan et al., 2007). Activation of PARP-1 was found at the earliest time point tested ( 5 min; Fig. $5 E$ ), but PAR immunoreactivity disappeared at later times, which is consistent with its rapid degradation by poly(ADP-ribose) glycohydrolase (PARG) (Koh et al., 2004). PARP-1 activation resulted in the accumulation of PAR in cell nuclei and was prevented by PARP-1 inhibitor PJ-34 (Fig. 5F). However, there was no difference in PAR accumulation between WT and SCaMC-3 KO neurons.

We next tested the effects of PARP-1 activation on the neuronal responses to NMDA. PARP-1 inhibitor 3-AB prevented depletion of cytosolic ATP levels in WT neurons from 200 s onward (Fig. 6A), in agreement with the known effects of PARP- 1 on NAD ${ }^{+}$and ATP consumption (Alano et al., 2010). In addition, 3-AB slightly prevented the rapid fall in $[\mathrm{ATP}]_{\mathrm{mit}}$ in WT neurons (Fig. $6 B$ ), but especially in SCaMC-3 KO neurons (Fig. 6C). Surprisingly, these different 3-AB concentrations had little effect in NMDA-induced respiratory stimulation in WT neurons but were able to overcome the lack of SCaMC-3 in KO neurons. In these neurons, $3-\mathrm{AB}$ allowed a dose-dependent increase in the initial respiratory responses to NMDA, reaching values identical to those of WT neurons (Fig. $6 D-F$ ). Preincubation with 5-20 $\mu \mathrm{M}$ PJ34 and 20 $\mu \mathrm{M} D P Q$ increased NMDA-induced respiratory stimulation both in WT and SCaMC-3 KO neurons, but the increase was clearly larger in the KO neurons (Fig. 6G). Furthermore, both inhibitors 
A

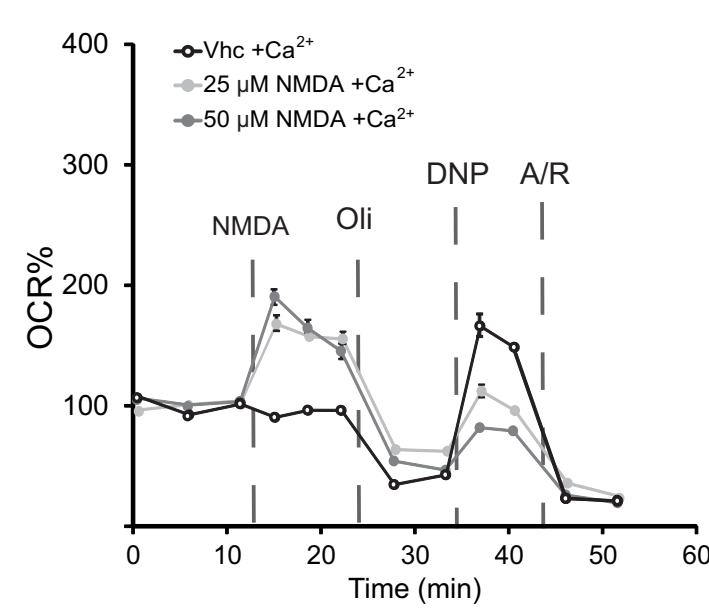

B

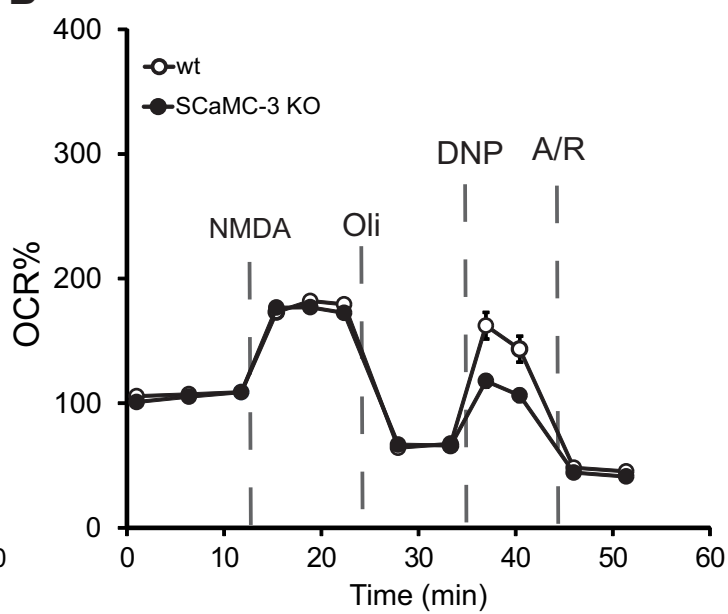

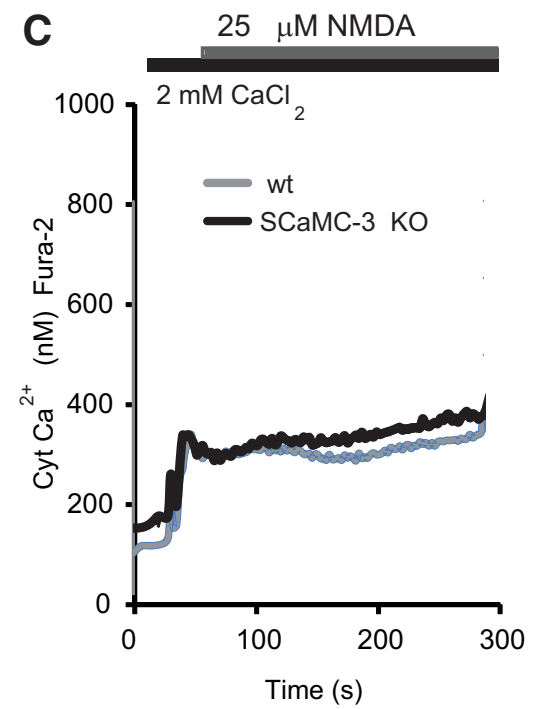

D

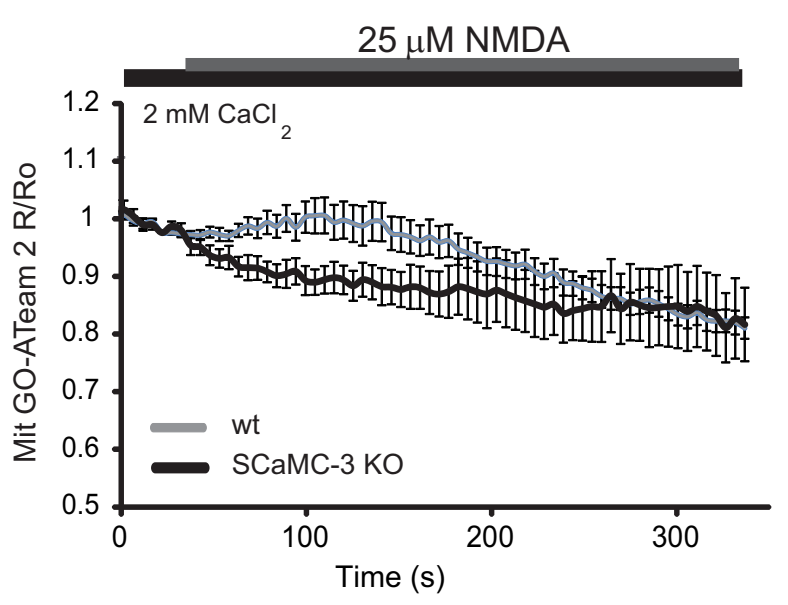

Figure 4. Low doses of NMDA promote maintenance of respiratory stimulation both in WT and SCaMC-3 KO neurons, but a differential mitochondrial ATP drop in the presence of the same cytosolic $\mathrm{Ca}^{2+}$ signal. $\boldsymbol{A}$, Vehicle (black trace), $25 \mu \mathrm{M}$ NMDA (light gray trace), or $50 \mu \mathrm{M}$ NMDA (dark gray trace) induced stimulation of OCR in cortical neurons in $2 \mathrm{~mm} \mathrm{Ca}{ }^{2+}$ medium. $\boldsymbol{B}$, The $25 \mu \mathrm{M}$ NMDA-induced stimulation of OCR in WT (blue trace) or SCaMC-3 KO (red trace) cortical neurons. C, Changes in $\left[\mathrm{Ca}^{2+}\right]_{\mathrm{cyt}}$ in Fura-2-loaded neurons obtained by stimulation with $25 \mu \mathrm{M} \mathrm{NMDA}$ in WT (blue trace) or SCaMC-3 KO (red trace) neurons; data are the mean of at least 30 neurons per condition of a representative experiment is shown. $\boldsymbol{D}$, Mitochondrial ATP in neurons transfected with mit-G0-ATeam2 stimulated with $25 \mu$ M NDA in WT (blue trace) or SCaMC-3 KO (red trace) neurons. Data are from at least 15 neurons from six experiments per genotype is shown.

partially prevented the fall in $[\mathrm{ATP}]_{\text {mit }}$ levels in SCaMC-3 KO neurons (Fig. $6 H$ ). These results indicate that NMDA-induced activation of PARP-1 causes a drastic fall in mitochondrial ATP, which is rescued by AdN uptake in mitochondria through SCaMC-3.

Earlier $\mathrm{Ca}^{2+}$ deregulation, lower $\mathrm{Ca}^{2+}$ retention capacity, and enhanced permeability transition pore opening probability in SCaMC-3 KO neurons and isolated SCaMC-3 KO mitochondria

We have next studied whether the early effects of mitochondrial AdN transport through SCaMC-3 had implications in glutamateinduced delayed $\mathrm{Ca}^{2+}$ deregulation (DCD). In cortical and cerebellar granule neurons, glutamate-induced transient increase in cytosolic $\mathrm{Ca}^{2+}$ is followed by a delayed irreversible rise in cytosolic $\mathrm{Ca}^{2+}$ named delayed calcium deregulation, or DCD (Tymianski et al., 1993). DCD occurs at the time of a collapse in the mitochondrial membrane potential (Abramov and Duchen, 2008; Duchen, 2012) and is followed by an acidification of the mitochondrial matrix (Bolshakov et al., 2008; Li et al., 2009), suggesting the involvement of permeability transition pore (PTP) opening. However, protection against excitotoxic neuronal death by cyclophilin D (CypD) deficiency, a signature of the PTP, is observed only under restricted conditions (Li et al., 2009).

In response to glutamate, $\mathrm{SCaMC}-3 \mathrm{KO}$ neurons also have a reduced stimulation of respiration and a larger mitochondrial $\mathrm{Ca}^{2+}$ peak, as observed for NMDA (results not shown). The initial $\left[\mathrm{Ca}^{2+}\right]_{\mathrm{i}}$ response to $100 \mu \mathrm{M}$ glutamate in cultured neurons from WT (top) and SCaMC-3 KO (bottom) mice was the same (Fig. 7A), as shown before for NMDA (Fig. 2E). Nevertheless, a clear difference in the response to glutamate among genotypes was observed at later times. Time to DCD (Li et al., 2009; Fig. 7B) was reduced in SCaMC-3-deficient neurons, while the percentage of cells undergoing DCD at $50 \mathrm{~min}$ (Fig. 7C) was notably higher in SCaMC-3 KO than in wild-type cultures.

The earlier appearance of DCDs in SCaMC-3 KO neurons may be associated with changes in the mitochondrial $\mathrm{Ca}^{2+}$ retention capacity due to SCaMC-3 deficiency. In liver (Amigo et al., 2013) and tumor cell mitochondria (Traba et al., 2012), $\mathrm{ATP}-\mathrm{Mg} / \mathrm{Pi}$ or $\mathrm{ADP} / \mathrm{Pi}$ exchange results in an increase in the $\mathrm{Ca}^{2+}$ retention capacity observed at physiological $(>1 \mathrm{~mm})$, 

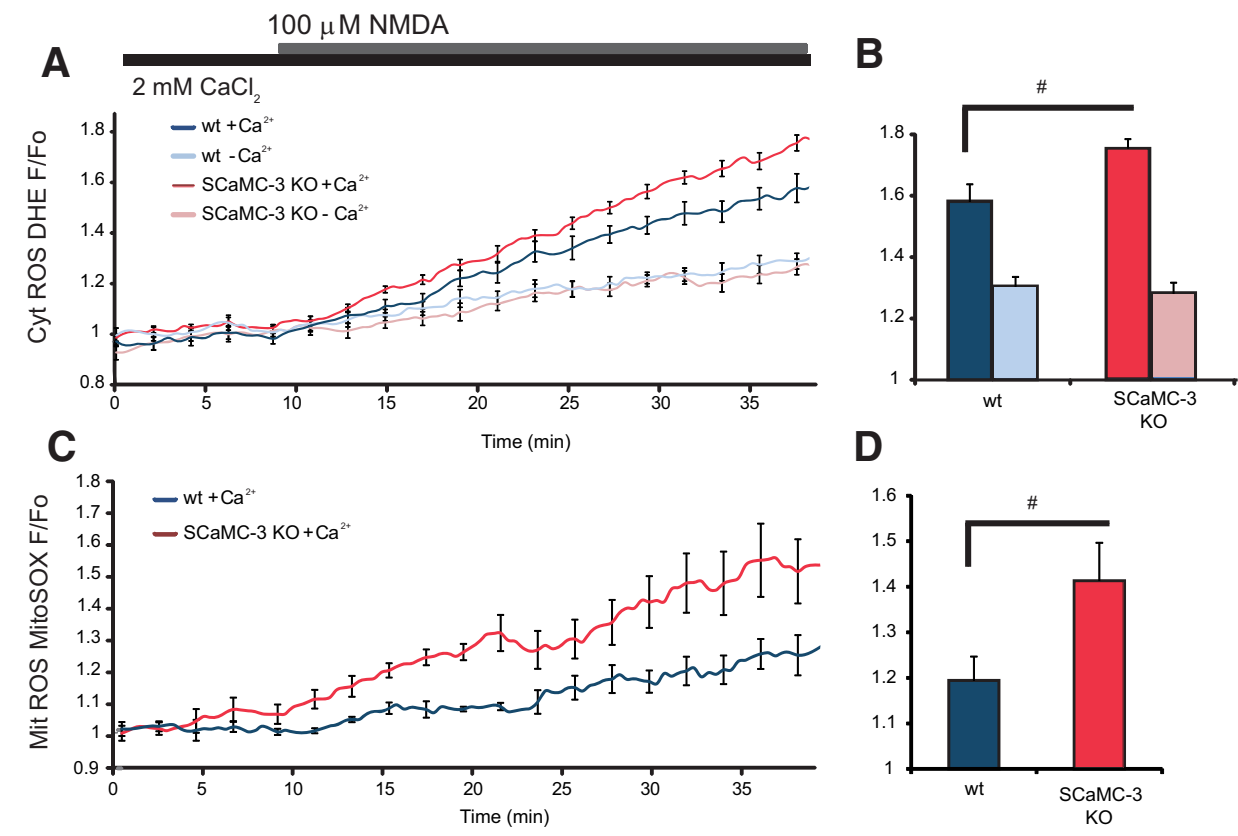

D
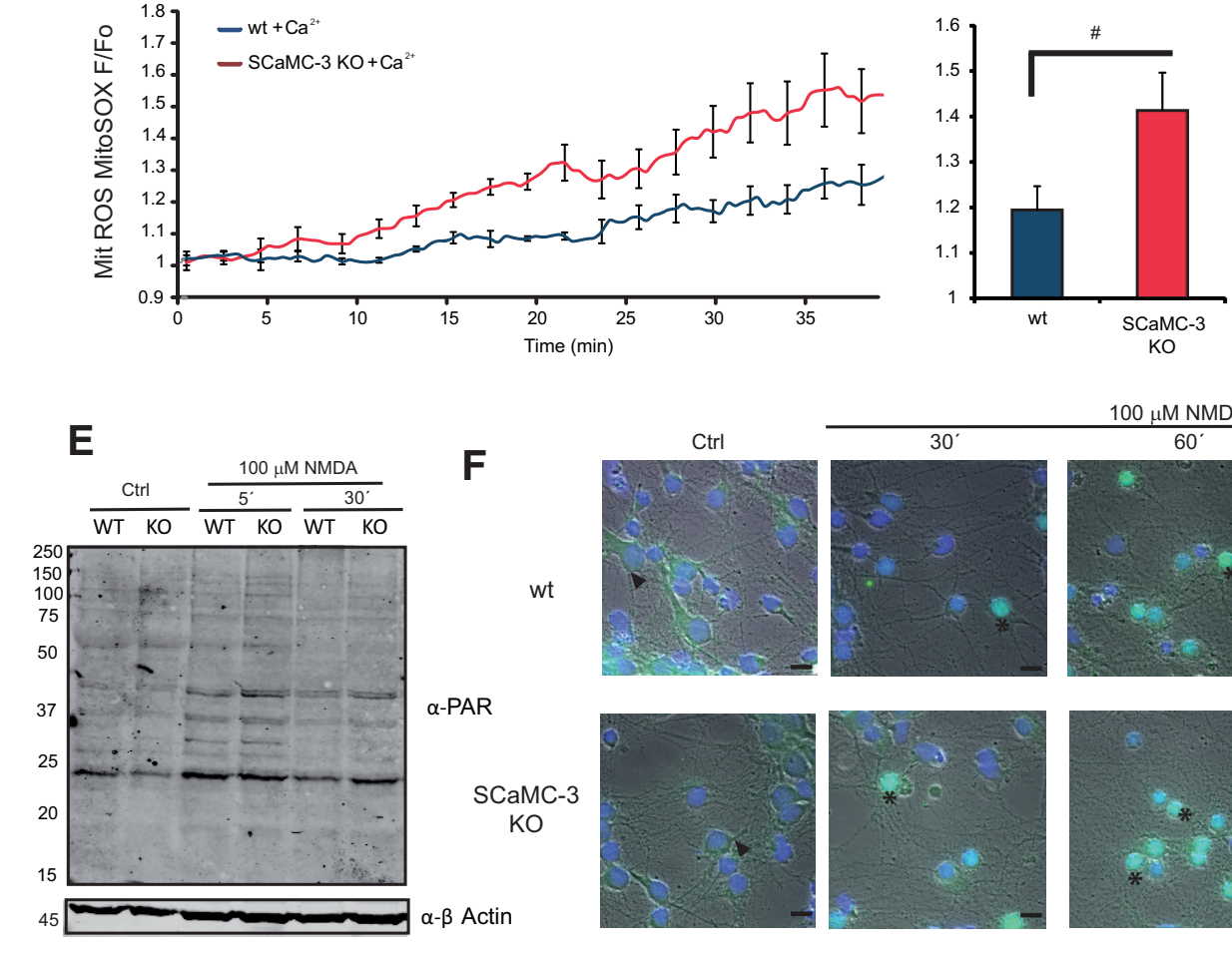

$100 \mu \mathrm{M}$ NMDA
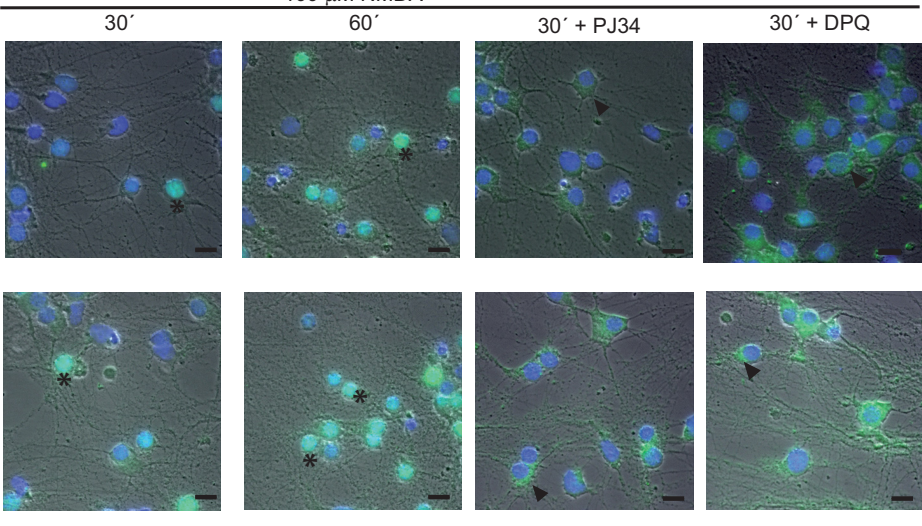

Figure 5. NMDA-induced production of cytosolic and mitochondrial ROS and PARP-1 activation. $A-D$, Cortical neurons from WT (blue traces) or SCaMC-3 KO (red traces) were loaded with $2 \mu m$ dihydroethidium and immediately recorded $(\boldsymbol{A}, \boldsymbol{B})$ or were incubated for $10 \mathrm{~min}$ with $3 \mu \mathrm{m}$ MitoSOX $(\boldsymbol{C}, \boldsymbol{D})$, which was washed off before recording in $2 \mathrm{~mm} \mathrm{Ca}^{2+}$ medium (dark traces) or $\mathrm{Ca}^{2+}$-free medium $(100 \mu \mathrm{m}$ EGTA; light traces) in a $37^{\circ} \mathrm{C}$ thermostatized plate fluorescence reader. After 10 min, neurons were subjected to $100 \mu \mathrm{m} \mathrm{NMDA} \mathrm{stimulation,} \mathrm{and} \mathrm{cytosolic} \mathrm{and} \mathrm{mitochondrial} \mathrm{ROS} \mathrm{production} \mathrm{was} \mathrm{analyzed.} \boldsymbol{B}, \boldsymbol{D}$, Fluorescence 30 min after NMDA addition (mean \pm SEM from at least 12 wells from representative experiments; \#p $<0.05$ ). $\boldsymbol{E}$, Western blot of immunoreactive proteins with anti-PAR antibody. $\boldsymbol{F}$, Immunostaining for PAR with DAPI as a nuclear marker and phase contrast images of WT or SCaMC-3 KO cortical neurons after $0-30$ min of NMDA exposure in the absence or presence of preincubation with PARP-1 inhibitors PJ-345 $\mu \mathrm{m}$ or DPQ $20 \mu \mathrm{m}$. Arrowheads indicate neurons with a diffuse PAR pattern, and asterisks indicate neurons with nuclear PAR accumulation. Scale bars, $10 \mu \mathrm{m}$.

but not at low $(0.2 \mathrm{mM})$, concentrations of ADP or ATP-Mg (Traba et al., 2012; Amigo et al., 2013). $\mathrm{Ca}^{2+}$-induced swelling in WT and SCaMC-3 KO liver or brain mitochondria was identical in the presence of $0.2 \mathrm{~mm}$ ADP (Fig. 7D1,E1) or the pore-forming peptide alamethicin (results not shown). In both types of mitochondria, $0.2 \mathrm{~mm}$ ADP was partially protective from swelling, possibly by interacting with the adenine nucleotide translocator (ANT) and triggering the " $\mathrm{m}$ " conformation of the carrier, as previously shown in liver mitochondria (Bernardi et al., 2006). On the other hand, in the presence of 1-2 mM ADP or ATP, WT mitochondria, but not KO mitochondria, showed an enhanced capacity to accumulate $\mathrm{Ca}^{2+}$ (Amigo et al., 2013) and a drastic decrease in $\mathrm{Ca}^{2+}$-induced swelling (Fig. 7D2,D3,E2). When $\mathrm{Mg}^{2+}$ was omitted from the buffer, ATP lost the capacity to provide additional protection to WT mitochondria, while ADP (which is transported in the $\mathrm{Mg}^{2+}$-free form; Fiermonte et al., 2004) still provided protection (Fig. 7D4,D5).
Cyclosporine A (CsA) inhibited $\mathrm{Ca}^{2+}$-induced swelling in liver and brain mitochondria in both genotypes (Fig. 7D6,E3). Accordingly, CsA increased $\mathrm{Ca}^{2+}$ retention capacity and carboxyatractyloside, an inhibitor of the ANT that stimulates PTP opening, strongly reduced $\mathrm{Ca}^{2+}$ retention in both WT and KO mitochondria, but in the presence of $1 \mathrm{~mm}$ ATP-Mg the differences between both genotypes were still observed (Fig. $7 F, G$ ). These effects of nucleotides were not due to a possible action on mitochondrial K-ATP channels (O’Rourke, 2004), as differences in swelling were still observed when experiments were conducted in a low (5 mM)- $\mathrm{K}^{+}$medium (results not shown).

Together, these results show that AdNs regulate PTP opening in brain mitochondria independently of ANT and CypD, via the ATP-Mg/Pi carrier SCaMC-3, and that the enhanced $[\mathrm{ATP}]_{\mathrm{mit}}$ depletion in SCaMC-3 KO neurons exposed to NMDA causes a decrease in mitochondrial $\mathrm{Ca}^{2+}$ retention capacity in neuronal SCaMC-3 KO mitochondria that contributes to the early appearance of DCDs in these neurons. 


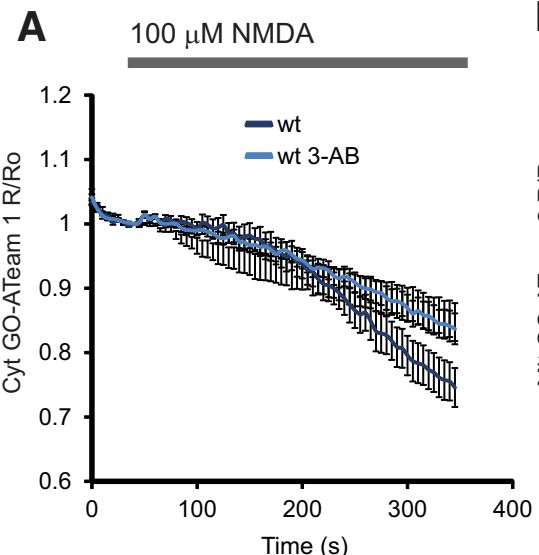

B

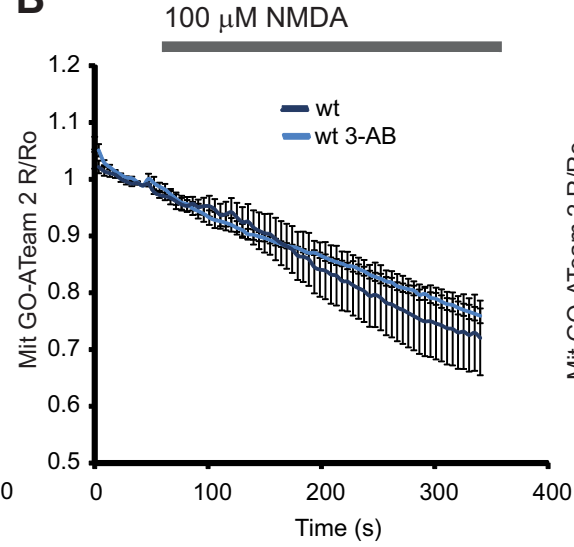

E

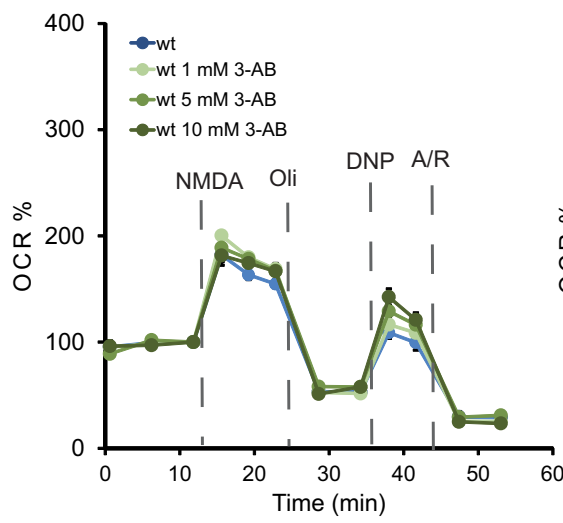

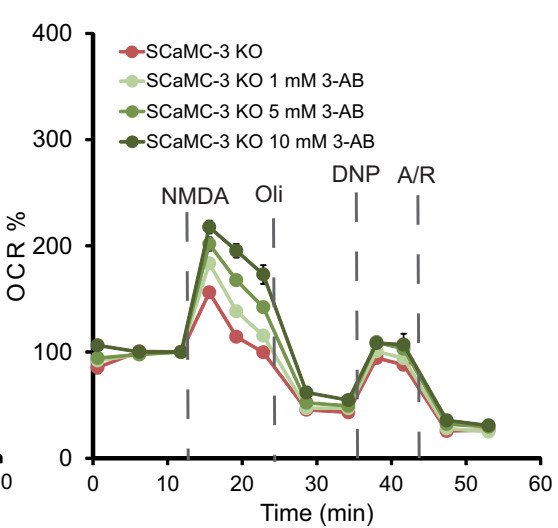

C $\quad 100 \mu \mathrm{M}$ NMDA

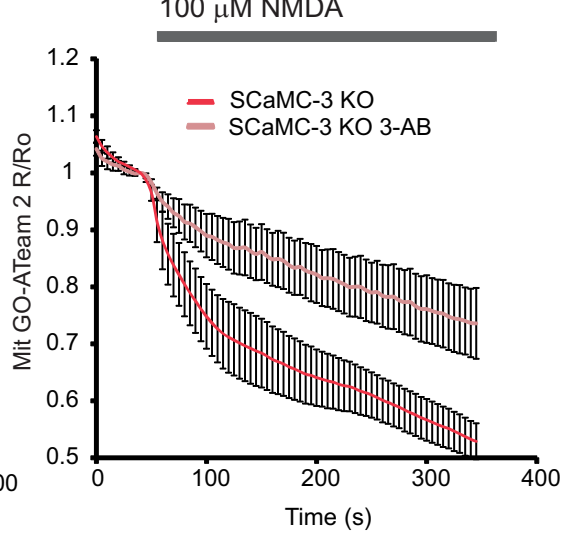

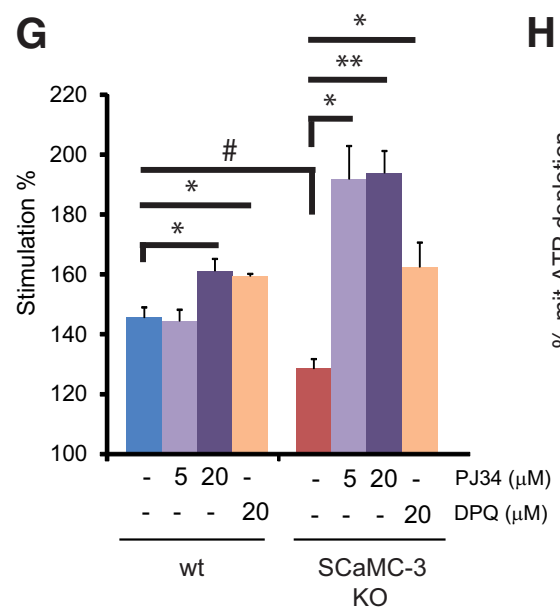

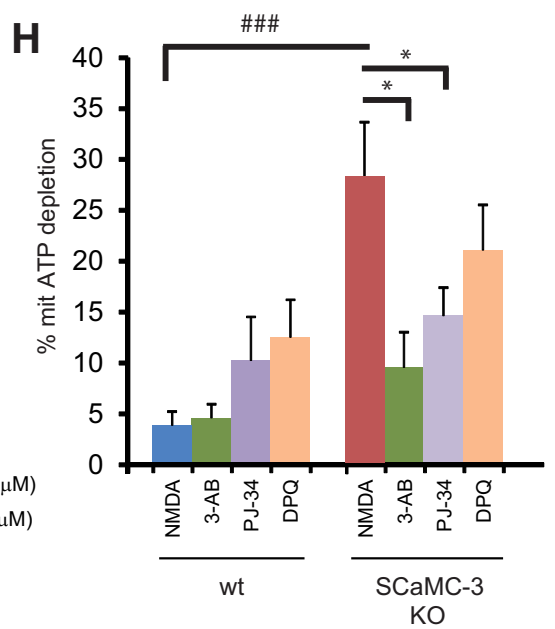

Figure 6. PARP-1 inhibitors prevent NMDA-induced drop of cytosolic and mitochondrial ATP, and recover the blunted NMDA-stimulated respiration in SCaMC-3 KO. $A-C$, Cytosolic (A) or mitochondrial ATP $(\boldsymbol{B}, \boldsymbol{C})$ in WT neurons ( $\boldsymbol{A}, \boldsymbol{B}$, blue traces) and SCaMC-3 KO neurons (C, red traces) transfected with cyt-GO-ATeam1 or mit-G0-ATeam 2 stimulated with $100 \mu \mu \mathrm{M}$ NMDA in control conditions (dark traces) or in the presence of $5 \mathrm{~mm} 3-\mathrm{AB}$ (light traces). $\boldsymbol{D}, \boldsymbol{E}, \mathrm{NMDA}$-induced stimulation of OCR in WT (D) or SCaMC-3 KO (E) cortical neurons in 2 mm Ca ${ }^{2+}$ medium in the presence or absence of 1, 5, or 10 mm 3-AB. $\boldsymbol{F}$, Stimulation of respiration at $3 \mathrm{~min}$ (as percentage of basal values) in experiments shown in $\boldsymbol{B}$ and $\boldsymbol{C}$. ( $n=6-9$ experiments). $\mathbf{G}$, Stimulation of respiration at 3 min in control conditions or in the presence of $5-20 \mu \mathrm{m} P J-34$ or 20 MIM DPQ in a separate set of three to six experiments. $\boldsymbol{H}$, Mitochondrial ATP depletion 50 s after NMDA in neurons transfected with mit-GOATeam 2 exposed to NMDA in the presence or absence of PARP-1 inhibitors $5 \mathrm{~mm} 3-\mathrm{AB}, 5 \mu \mathrm{m} \mathrm{PJ}-34$, or $20 \mu \mathrm{m} \mathrm{DPQ}$. Data from at least 15 neurons, different experiments, and different platings are shown. ${ }^{*}, \# p \leq 0.05,{ }^{* *} p \leq 0.01$, \#\#\#, $\left.{ }^{* * *} p \leq 0.001\right)$.

SCaMC-3 deficiency increases vulnerability to glutamate excitotoxicity in vitro and in vivo with no changes in neuronal excitability

Having shown that NMDA causes a decrease in $[\mathrm{ATP}]_{\text {mit }}$ and earlier appearance of DCDs in SCaMC-3 KO neurons, we tested whether this was associated with enhanced vulnerability to excitotoxicity. Cortical neuronal cultures were exposed to $10-100$ $\mu \mathrm{M}$ glutamate during $5 \mathrm{~min}$, and death was evaluated $6 \mathrm{~h}$ later. Neuronal death was increased in the absence of SCaMC- 3 at all glutamate concentrations (Fig. 8A). A similar treatment with 100 $\mu \mathrm{M}$ NMDA induced a lower level of neuronal death than glutamate (Fig. $8 B$ ), possibly due to the fact that $\mathrm{Na}^{+}$and $\mathrm{Ca}^{+}$concentrations rose to lower levels than those observed for $100 \mu \mathrm{M}$ glutamate (results not shown) and that metabolic consequences 
A
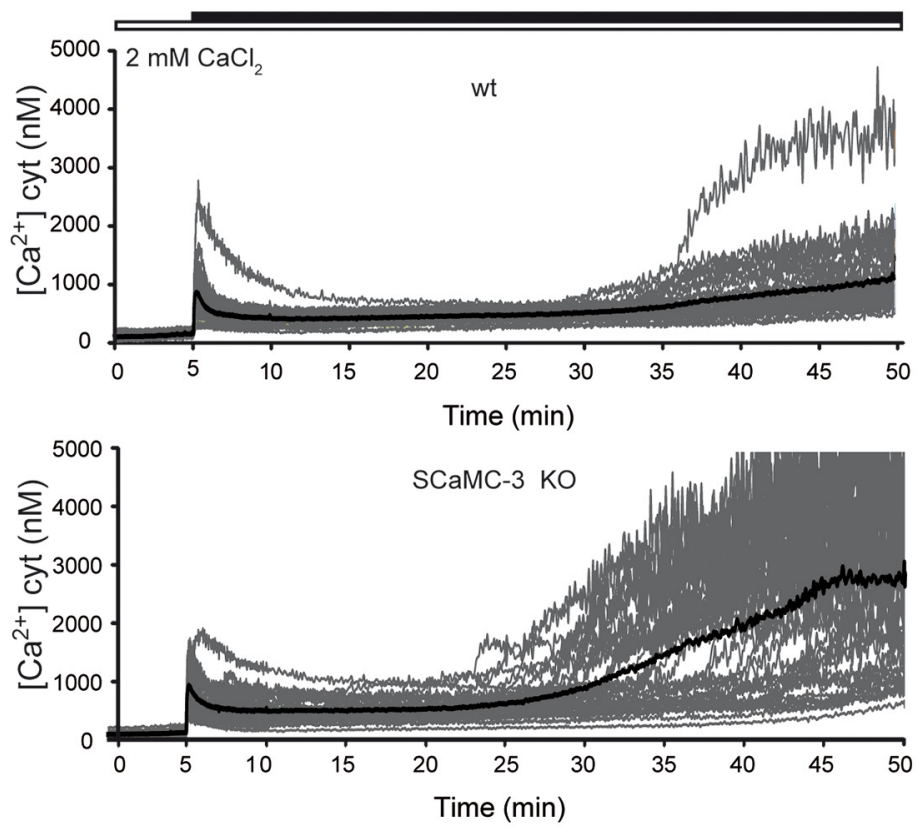

B $\square w t$

SCaMC-3 KO

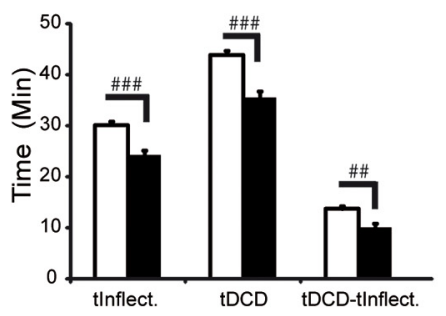

C

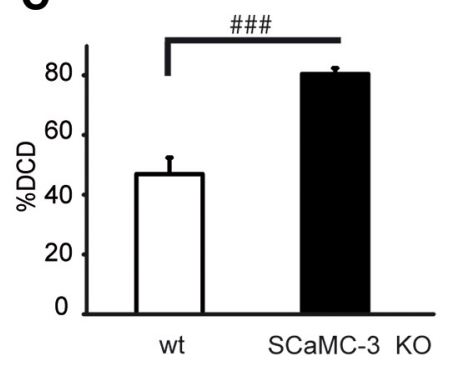

$\mathbf{E}$

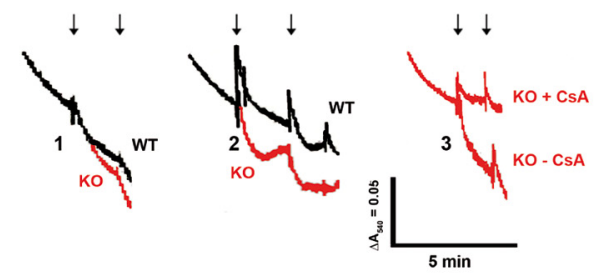

ADP $0.2 \mathrm{mM}$

ATP-Mg $1 \mathrm{mM}$

ATP-Mg $1 \mathrm{mM}$
$\mathbf{F}$

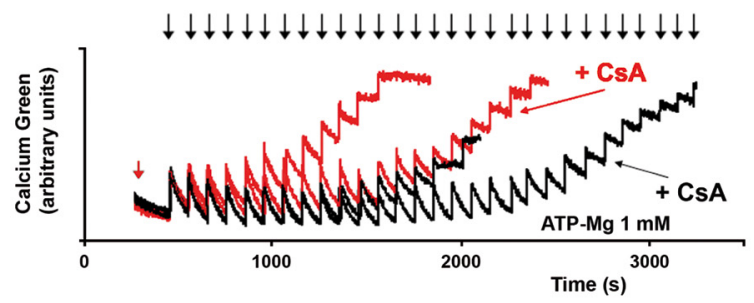

G

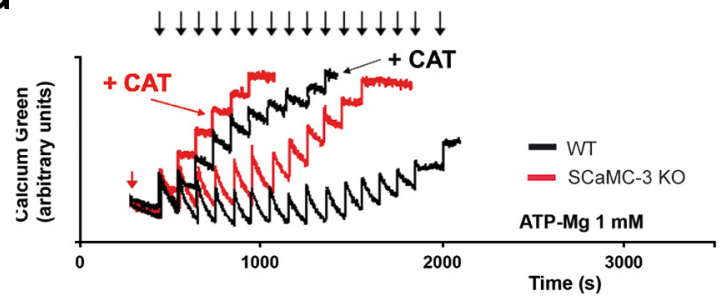

Figure 7. Effects of SCaMC-3 deficiency on neuronal DCDs and $\mathrm{Ca}^{2+}$-induced swelling and $C R C$ in isolated mitochondria. $A$, Changes in $\left[\mathrm{Ca}^{2+}\right]_{\mathrm{cyt}}$ in Fura-2-loaded neurons upon $100 \mu \mu \mathrm{MMDA}$ exposure in WT (top) or SCaMC-3 KO (bottom) neurons. Individual cell recordings (in gray) and averages (thick black trace) were shown. The results correspond to a representative experiment. $\boldsymbol{B}$, Time to inflection (tInflect; i.e., time delay to the start of cytosolic $\mathrm{Ca}^{2+}$ rise after the peak), time to DCD (tDCD; i.e., delay to the onset of secondary $\mathrm{Ca}^{2+}$ raise), and the difference between them are shown. The differences for $\mathrm{HDCD}$ were $44.83 \pm 1.27$ versus $35.73 \pm 1.51 \mathrm{~min}$ for WT and SCaMC- $3 \mathrm{KO}$ neurons $(n=43 \mathrm{WT} n=42 \mathrm{KO} ; p \leq 0.001)$. C, Quantification of the percentage of cells undergoing $D C D$ at $50 \mathrm{~min}, 46.9 \pm 5.5$ versus $80.41 \pm 2.0 \%$ in WT and SCaMC- 3 KO neurons; $p \leq 0.001$. Cells that did not undergo DCD after 50 min recording were arbitrarily given a tDCD of 50 min. Data are from at least four independent platings. D, Swelling of isolated liver mitochondria from WT (black traces) and SCaMC-3 K0 mice (red traces). Swelling was induced after subsequent $\mathrm{Ca}^{2+}$ pulses (arrows, $20 \mu \mathrm{m}$ each) and measured as a decrease in light scattering (as absorbance at $540 \mathrm{~nm}$ ) in the presence of ADP $0.2 \mathrm{~mm}$ (1), ATP-Mg $1 \mathrm{~mm}$ (2), ADP-Mg $2 \mathrm{~mm}$ (3), ATP $1 \mathrm{~mm}$ (4), ADP $2 \mathrm{~mm}(\mathbf{5})$, and ATP-Mg Pi in the presence or absence of $5 \mu \mathrm{M}$ (SA (6). E, Swelling of isolated brain mitochondria after subsequent $\mathrm{Ca}^{2+}$ pulses in the presence of ADP $0.2 \mathrm{~mm}$ (1) and ATP-Mg 1 $\mathrm{mm}$, and in the presence or absence of CSA $5 \mu \mathrm{M}(\mathbf{2}, 3) . F, G$, CRC was measured in WT (black traces) and SCaMC-3 KO (red traces) isolated liver mitochondria by using the $\mathrm{Ca}^{2+}$-sensitive probe Calcium-Green $5 \mathrm{~N}(0.1 \mu \mathrm{M})$ in the extramitochondrial space in the presence of $1 \mathrm{~mm}$ ATP-Mg and $5 \mu \mathrm{M}$ CSA (F) or $10 \mu \mathrm{m}$ carboxyatractyloside (CAT) (G). Representative experiments are shown. $\# \# p \leq 0.01 \# \# p \leq 0.001$, two-tailed unpaired Student's $t$ test.

of sustained $\mathrm{Na}^{+}$elevations may lead to the failure of ionic homeostasis in dendrites preceding $\mathrm{Ca}^{2+}$-dependent cellular compromise (Vander Jagt et al., 2009). Neuronal death was again increased in SCaMC-3 KO neurons. The presence of PARP-1 inhibitors $3-\mathrm{AB}$ or $\mathrm{PJ} 34$ during the exposure and the recovery periods did not protect against NMDA-induced death in WT neurons, but overcame the effect of SCaMC-3 deficiency in $\mathrm{KO}$ neurons. (Fig. 8B).
To analyze the increased susceptibility of SCaMC-3-deficient neurons to glutamate/NMDA-induced cell death in an in vivo context, we studied KA-induced seizures by injecting KA intraperitoneally into age-matched SCaMC-3 KO and wild-type mice. Kainate seizures arise from massive neuronal depolarization due to activation of kainate receptors and $\mathrm{Na}^{+}$and $\mathrm{Ca}^{2+}$ influx into the neuron (Cheng and Sun, 1994; Gimenez-Cassina et al., 2012), which promote enhanced metabolic activity (Ben-Ari, 1981; Al- 
A

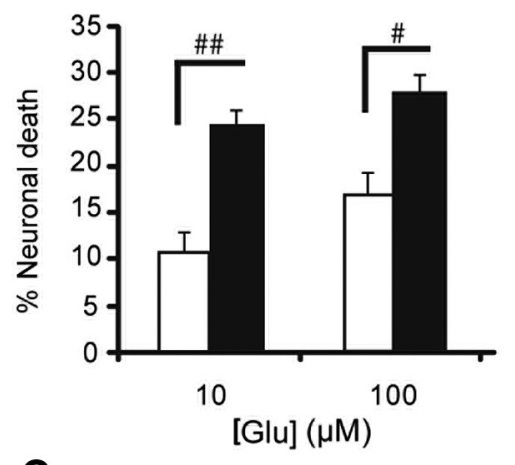

C

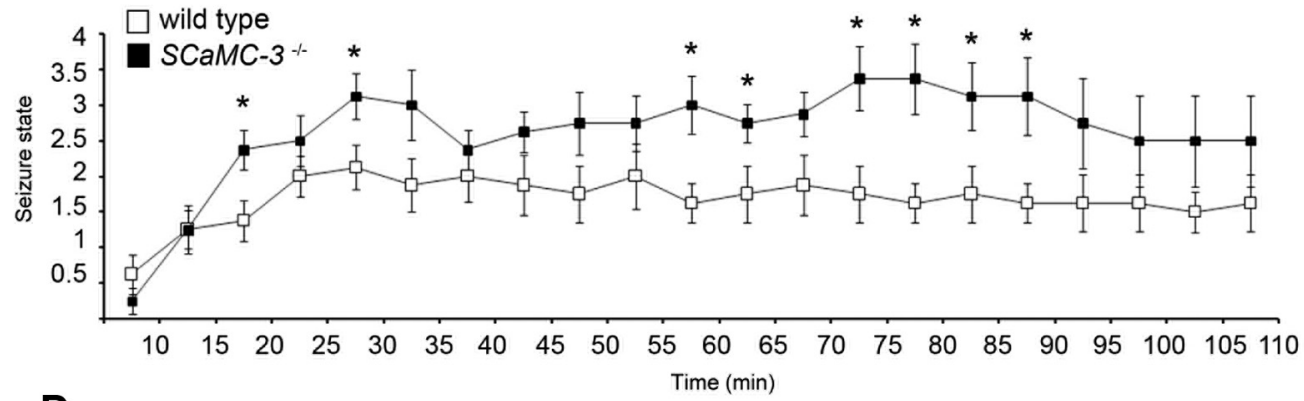

D
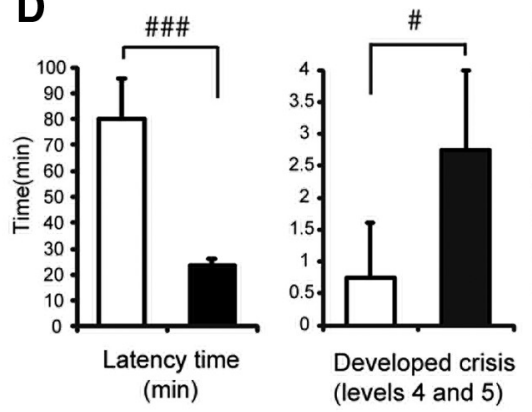

E
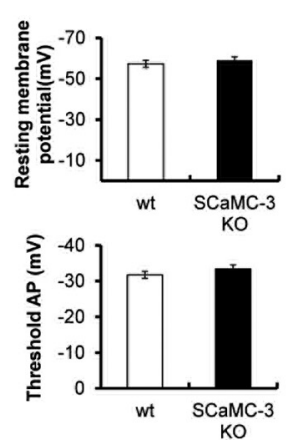

G

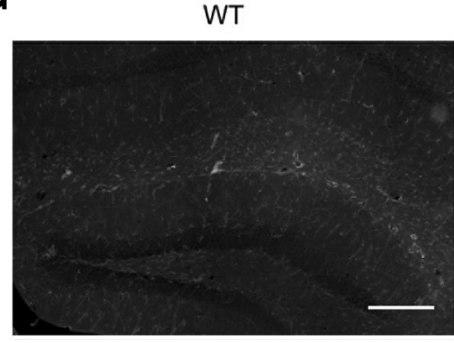

B

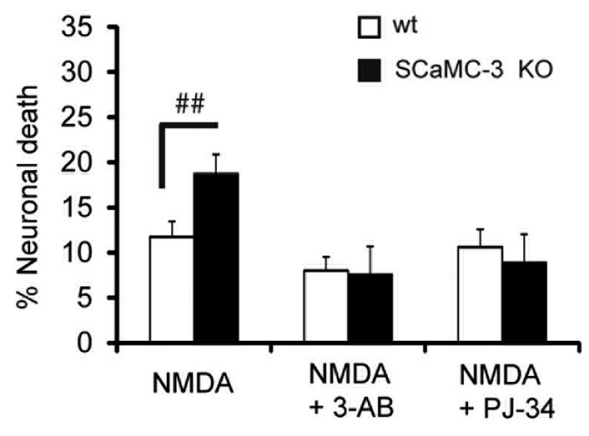


bala et al., 1984), increasing ATP demand. Secondarily, kainateinduced depolarization will release glutamate, which activates all types of glutamate receptors, particularly NMDA receptors, closing a feedforward cycle promoting long-term damage (Rodríguez-Moreno and Sihra, 2004; Fujikawa, 2005; Vincent and Mulle, 2009). Defects in mitochondrial $\mathrm{Ca}^{2+}$ handling, such as that caused by Letm1 deficiency, result in higher seizure severity after kainic acid administration (Jiang et al., 2013). The seizure profile of animals from both genotypes during $2 \mathrm{~h}$ after KA administration was monitored. Initial scores were the same in WT and SCaMC-3 KO mice. From 15 min onward, mice lacking SCaMC-3 display a worse outcome (Fig. 8 C). SCaMC-3 KO mice showed high score crises $(>4)$ earlier and in higher numbers than controls (Fig. $8 D$ ), and all parameters calculated to evaluate the appearance and severity of seizures are consistent with an increased susceptibility in SCaMC-3 KO animals.

Increased seizure profile in SCaMC-3 KO neurons may be due to an increased excitability or to the deleterious consequences of massive glutamate release. To test these hypotheses, we studied the electrophysiological properties of SCaMC-3 KO neurons. We analyzed whole-cell current-clamp recordings for passive cell membrane properties (resting membrane potential and input resistance), active membrane properties (action potential threshold and amplitude), and, finally, spiking capacity, which was measured as the number of APs in response to a given input current in WT and SCaMC-3 KO cortical cells cultured in vitro. We detected no differences in passive or active membrane properties in SCaMC-3 KO in vitro cultured neurons when compared with control neurons (Fig. 8E,F). The lack of changes in neuronal excitability is consistent with the lack of variations among

\footnotetext{
Figure 8. SCaMC-3 KO neurons show an increased vulnerability to glutamate excitotoxicity and a higher seizure level after kainate injection. $A$, Average neuronal death of cortical neurons from WT (white bars) and SCaMC-3 KO (black bars) $6 \mathrm{~h}$ after 5 min glutamate exposure evaluated by calcein-propidium iodide staining. Differences for $10 \mu \mathrm{M}$ Glu $(10.35 \pm 2.7 \%$ vs $24.43 \pm 1.6 \%$ for WT and SCaMC-3 KO neurons; \#\#p $\leq 0.001)$ and $100 \mu \mathrm{m}$ Glu (16.4 $\pm 1.59 \%$ vs $26.70 \pm 1.9 \%$ for WT and SCaMC-3 KO neurons; $\# p=0.02$ ). The results were obtained from at least three independent platings, averaged independently and compared. $\boldsymbol{B}$, Neuronal death $6 \mathrm{~h}$ after a $5 \mathrm{~min} 100 \mu \mathrm{m}$ NMDA exposure in the presence or absence of $5 \mathrm{~mm} 3-\mathrm{AB}$ or $0.4 \mu \mathrm{m}$ PJ34. The differences for $100 \mu \mathrm{M}$ NMDA exposure were $11.7 \pm 1.8 \%$ versus $18.70 \pm 2.2 \%$ for WT and SCaMC-3 KO neurons (\#\# $\leq 0.01)$. Data from a representative experiment are shown. C, D, SCaMC3-KO mice show increased susceptibility to KA-induced seizures. Mice were administered intraperitoneally with $\mathrm{KA}(25 \mathrm{mg} / \mathrm{kg})$, and seizure appearance and severity were monitored using Racine's scale (see Materials and Methods). C, Seizure profile of wild-type and SCaMC-3 KO mice after KA treatment. Seizure appearance, with the most severe state every 5 $\mathrm{min}$, is plotted against time for $2 \mathrm{~h}$. For the statistical analysis, normality and variance homogeneity of the data were confirmed using Shapiro-Wilk's and Levene's tests, respectively, and a factorial ANOVA was performed using the severity of the crisis as the dependent variable, and time and genotype as independent variables $\left(n=8\right.$ male mice from each genotype; ${ }^{*} p<$ 0.05). D, Mean values of different parameters of seizure appearance and severity: "latency time" is the time of appearance of the first state 4 crisis after KA administration; "developed crisis" is the number of state 4 and state 5 crises that developed during the experiment; "accumulative score" is the result of arithmetically adding all states recorded; and "mean level" is the mean of those states (\#p $<0.05$; \#\#\# $p<0.001$, paired two-tailed Student's $t$ test). $\boldsymbol{E}$, Neuronal excitability and firing patterns of WT $(n=26)$ and SCaMC-3 KO $(n=28)$ neurons obtained from patch-clamp recordings from neuronal cultures at $8-9$ DIV. Resting membrane potential, action potential threshold, and amplitude and input resistance are shown. $\boldsymbol{E}$, Plot of the number of action potentials elicited by increasing input currents obtained from the same cells. Values for wt (white dots) versus SCaMC-3 KO neurons (black dots) are shown. $\mathbf{G}$, Immunohistochemistry of representative hippocampal sections from kainic acid-treated wild-type and SCaMC-3 KO brains using GFAP antibody. $\boldsymbol{H}$, Fluorescence quantification of GFAP in hippocampal areas represented as the percentage of the hippocampus area occupied by GFAP signal using ImageJ software (see Materials and Methods; $n=7 ; \# p<0.01$, paired two-tailed Student's $t$ test). Images were taken and processed using identical conditions and settings. Scale bars, $100 \mu \mathrm{m}$.
}

genotypes in the initial seizure profile (Fig. 8C). Although alterations in synaptic efficacy (increased excitatory or decreased inhibitory drive) as a possible basis for differences in seizure threshold cannot be excluded, the increased seizure scores at later times in SCaMC-3 KO mice are most likely due to increased neuronal damage after kainate insult. We failed to observe neuronal death by Fluoro-Jade B staining, probably due to the strong resistance of $\mathrm{C} 57 \mathrm{BL} / 6$ mice to kainate-induced neurodegeneration (McCord et al., 2008; Vincent and Mulle, 2009). However, and consistent with this hypothesis, we found enhanced astrogliosis measured by GFAP staining in the SCaMC-3 KO hippocampus $7 \mathrm{~d}$ after kainate exposure (Fig. $8 G, H$ ), which is indicative of increased damage.

Together, the results clearly show that SCaMC-3 deficiency increases neuronal vulnerability to excitotoxicity both in vitro and in vivo.

\section{Discussion}

Glutamate is the main excitatory neurotransmitter, and its actions in postsynaptic neurons lead to considerable ATP consumption and compensatory ATP production (Jekabsons and Nicholls, 2004; Nicholls, 2008; Duchen, 2012), which participate in decoding glutamate signals. However, excessive stimulation by glutamate also contributes to neuronal death through a process known as excitotoxicity (Olney and Sharpe, 1969). $\mathrm{Ca}^{2+}$ overload is thought to play a major role in excitotoxicity (Stout et al., 1998; Qiu et al., 2013) and studies with different animal and cellular models have revealed that ATP depletion in cytosol (Budd and Nicholls, 1996), PARP-1 activation (Andrabi et al., 2011), and PTP opening (Li et al., 2009) take place after persistent $\mathrm{Ca}^{2+}$ entry through NMDA receptors, and are involved in subsequent neuronal death. However, the role of mitochondrial AdN content in this context is unknown. In this study, we have addressed the contribution of the main ATP-Mg/Pi carrier expressed in brain, SCaMC-3, through its capacity to change the mitochondrial AdN pool, in the early neuronal response to NMDA and in protection against excitotoxic neuronal death.

With a variety of experimental approaches, ranging from $\mathrm{Ca}^{2+}$ transport in isolated mitochondria and respirometry in intact neurons to behavioral seizure monitoring in vivo, we provide evidence for the role of SCaMC-3 in the maintenance of mitochondrial ATP levels throughout excitotoxicity in vitro and in vivo. We have found that (1) $\mathrm{Ca}^{2+}$ activation of SCaMC-3 is required immediately after NMDA exposure to maintain mitochondrial ATP and at later times to maintain cytosolic ATP levels; (2) SCaMC-3 KO neurons undergo a rapid fall in mitochondrial ATP in response to glutamate or NMDA, which prevents full upregulation of respiration; (3) PARP-1 inhibitors prevent the early drop in mitochondrial ATP induced by NMDA and overcome the effects of SCaMC-3 deficiency in NMDA-induced activation of respiration; (4) SCaMC-3 KO neurons show earlier DCDs that are possibly related to the decrease in $\mathrm{Ca}^{2+}$ retention capacity of SCaMC-3-deficient mitochondria incubated with AdNs; and (5) SCaMC-3-deficient neurons and mice are more vulnerable to excitotoxicity with higher neuronal death after in vitro exposure to glutamate or NMDA, and an enhanced convulsive phenotype after in vivo kainate treatment. As enhanced seizures are unrelated to changes in neuronal excitability, and are followed by a larger astrogliosis, the results unveil a role of ScaMC-3 in protecting against excitotoxicity.

Along with $\mathrm{Ca}^{2+}$ entry in the cytosol and mitochondria, glutamate/NMDA is known to cause a rapid increase in respiration, which decays later on, before detectable changes in cell death take 
place (Jekabsons and Nicholls, 2004; Yadava and Nicholls, 2007; Gleichmann et al., 2009). This decrease, which results in a fall in maximal uncoupled respiration, or "spare respiratory capacity," reflects mitochondrial dysfunction (Yadava and Nicholls, 2007). We found that the initial large increase in OCR in response to NMDA was dependent upon the presence of external $\mathrm{Ca}^{2+}$, not through the effects of $\mathrm{Ca}^{2+}$ in increasing ATP breakdown (i.e., energy demand), but due to the role of $\mathrm{Ca}^{2+}$ in regulating respiration. $\mathrm{Ca}^{2+}$ upregulation of respiration is required to maintain neuronal ATP levels in response to changes in workload (Llorente-Folch et al., 2013) and to maintain ATP levels in synaptic terminals in response to activity changes (Rangaraju et al., 2014).

Now we find that the maintenance of mitochondrial matrix ATP levels in response to NMDA stimulation requires SCaMC-3. $\mathrm{Ca}^{2+}$ signals induced by NMDA activate AdN transport into mitochondria through SCaMC-3, counteracting the NMDAinduced fall in $[\mathrm{ATP}]_{\mathrm{mit}}$, and allow the full upregulation of oxidative phosphorylation (OXPHOS). As the SCaMC-3-induced changes in $[\mathrm{ATP}]_{\text {mit }}$ parallel those of coupled respiration, it is likely that the ATP synthesis mechanism, ATP synthase itself, and/or ANT, the ATP/ADP exchanger, is the ATP-sensitive process that responds to NMDA- and SCaMC-3-dependent changes in matrix ATP. ATP synthase activity, through its low-affinity site for ADP (100-200 $\mu \mathrm{M}$; Tomashek et al., 2004) and/or sensitivity to the mass action ratio of matrix AdNs, may explain the effect of SCaMC-3 deficiency on coupled respiration. $[\mathrm{ATP}]_{\mathrm{mit}}$ is far more sensitive to OXPHOS variations than $[\mathrm{ATP}]_{\text {cyt }}$ (Kioka et al., 2013), and the increased coupled respiration in response to NMDA probably accounts for the preservation of cytosolic ATP levels during NMDA exposure and also to lower ROS production, as the inhibition of coupled respiration is associated with a higher ROS production by mitochondria (Clapham et al., 2000; Formentini et al., 2014). On the other hand, increases in matrix ADP levels after SCaMC-3-mediated uptake in mitochondria may contribute to the activation of Krebs cycle dehydrogenases, which are sensitive to both matrix $\mathrm{Ca}^{2+}$ and ADP (Nichols et al., 1994; Glancy and Balaban, 2012), and thus to the full respiratory response.

A surprising finding of this work is the role of a PARP-1related process in the early fall in $[\mathrm{ATP}]_{\text {mit }}$ caused by NMDA exposure. It has long been established that PARP-1 (and PARP-2) activation upon NMDA exposure is involved in early mitochondrial depolarization (Abramov and Duchen, 2008; Alano et al., 2010; Duchen, 2012). PARP activation causes mitochondrial dysfunction either through direct action of PAR polymers on mitochondria (Andrabi et al., 2011; Virág et al., 2013) or indirectly by limiting substrate supply to mitochondria through PARP-1dependent consumption of cytosolic, but not mitochondrial, $\mathrm{NAD}^{+}$and inhibition of glycolysis (Alano et al., 2010; Kim et al., 2011; Duchen, 2012). Strikingly, we now find that the rapid fall in $[\mathrm{ATP}]_{\text {mit }}$ caused by NMDA exposure in SCaMC-3-deficient neurons is prevented by PARP-1 inhibitors, particularly $3-\mathrm{AB}$, with a smaller effect in the case of PJ-34 or DPQ, in accordance with the role of $[\mathrm{ATP}]_{\text {mit }}$ in OXPHOS stimulation; these inhibitors also upregulate respiration in SCaMC-3 KO neurons. The connection between PARP-1 activation and the fall in $[\mathrm{ATP}]_{\text {mit }}$ is still unknown. Mitochondrial PARP-1 activity has been detected in brain (Du et al., 2003; Lai et al., 2008), and the $\mathrm{NAD}^{+}$salvage pathway, which would drain ATP, has also been found in mammalian mitochondria (Yang et al., 2007; but see Pittelli et al., 2010). On the other hand, it has been proposed that PAR degradation through PARG and free ADP-ribose causes an increase in cytosolic AMP, which blocks ADP/ATP exchange through ANT (Formentini et al., 2009) and could have an impact on matrix ATP levels. Recently, two different groups have reported a direct action of PAR polymers in mitochondria-associated hexokinase 1 , leading to substrate supply impairment and resulting in mitochondrial ATP depletion after PARP-1 activation (Andrabi et al., 2014; Fouquerel et al., 2014). Whether this occurs in neurons in such a short time window is unknown.

The lack of AdN uptake through SCaMC-3 in response to NMDA not only causes a blunted increase in respiration, but also results in an earlier appearance of DCDs. This is probably related to the lower $\mathrm{Ca}^{2+}$ retention capacity of SCaMC-3 KO mitochondria in the presence of millimolar AdNs. The recent findings relating ATP synthase through its c-ring (Bonora et al., 2013) or ATP synthase dimers (Giorgio et al., 2013) as molecular components of the PTP open the possibility that a direct effect of matrix adenine nucleotides on the ATP synthase is involved in these effects.

Paradoxically, reduced $[\mathrm{ATP}]_{\text {mit }}$ and $\mathrm{Ca}^{2+}$ retention capacity of mitochondria result in higher matrix free $\mathrm{Ca}^{2+}$ levels, as observed in SCaMC-3 KO neurons during the initial response to NMDA (Fig. 2N), and in SCaMC-1 deficient cell lines (Traba et al., 2012). The reasons for this paradox are not well known but may be related to the behavior of isolated mitochondria, which appeared to contract (an increase in light scattering) immediately after $\mathrm{Ca}^{2+}$ uptake in the presence of $1 \mathrm{~mm} \mathrm{ATP-Mg}$, while KO mitochondria did not (results not shown). This has been previously observed in mitochondria of 143B and Cos-7 cells, and in brain mitochondria (Chalmers and Nicholls, 2003; Kristián et al., 2006; Traba et al., 2012) and may reflect the formation of $\mathrm{Ca}^{2+}$-Pi precipitates, which decrease levels of matrix free $\mathrm{Ca}^{2+}$ (de la Fuente et al., 2012) and perhaps direct chelation of $\mathrm{Ca}^{2+}$ by the nucleotides (Haumann et al., 2010).

The maintenance of $[\mathrm{ATP}]_{\text {mit }}$ through SCaMC-3 activity antagonizes $[\mathrm{ATP}]_{\mathrm{mit}}$ depletion caused by PARP-1, allows the preservation of $\mathrm{Ca}^{2+}$ retention capacity in neuronal mitochondria upon exposure to NMDA, and provides protection against NMDA excitotoxicity and kainate-induced seizures. Glutamate excitotoxicity plays a prominent role in delayed neurodegeneration following prolonged seizure activity, and the lack of SCaMC-3 by increasing the vulnerability to glutamate/NMDA excitotoxicity results in increased astrogliosis, indicating that SCaMC-3 effects observed in vitro are also present in vivo. These properties of SCaMC-3 make it a promising target in strategies aimed at increasing resistance to excitotoxicity.

\section{References}

Abramov AY, Duchen MR (2008) Mechanisms underlying the loss of mitochondrial membrane potential in glutamate excitotoxicity. Biochim Biophys Acta 1777:953-964. CrossRef Medline

Abramov AY, Duchen MR (2010) Impaired mitochondrial bioenergetics determines glutamate-induced delayed calcium deregulation in neurons. Biochim Biophys Acta 1800:297-304. CrossRef Medline

Alano CC, Garnier P, Ying W, Higashi Y, Kauppinen TM, Swanson RA (2010) $\mathrm{NAD}+$ depletion is necessary and sufficient for poly(ADP-ribose) polymerase-1-mediated neuronal death. J Neurosci 30:2967-2978. CrossRef Medline

Albala BJ, Moshé SL, Okada R (1984) Kainic-acid-induced seizures: a developmental study. Brain Res 315:139-148. Medline

Amigo I, Traba J, Satrústegui J, del Arco A (2012) SCaMC-1 like a member of the mitochondrial carrier (MC) family preferentially expressed in testis and localized in mitochondria and chromatoid body. PLoS One 7:e40470. CrossRef Medline

Amigo I, Traba J, González-Barroso MM, Rueda CB, Fernández M, Rial E, Sánchez A, Satrústegui J, Del Arco A (2013) Glucagon regulation of ox- 
idative phosphorylation requires an increase in matrix adenine nucleotide content through $\mathrm{Ca} 2+$ activation of the mitochondrial ATP-Mg/Pi carrier SCaMC-3. J Biol Chem 288:7791-7802. CrossRef Medline

Andrabi SA, Kim NS, Yu SW, Wang H, Koh DW, Sasaki M, Klaus JA, Otsuka T, Zhang Z, Koehler RC, Hurn PD, Poirier GG, Dawson VL, Dawson TM (2006) Poly(ADP-ribose) (PAR) polymer is a death signal. Proc Natl Acad Sci U S A 103:18308-18313. CrossRef Medline

Andrabi SA, Kang HC, Haince JF, Lee YI, Zhang J, Chi Z, West AB, Koehler RC, Poirier GG, Dawson TM, Dawson VL (2011) Iduna protects the brain from glutamate excitotoxicity and stroke by interfering with poly(ADP-ribose) polymer-induced cell death. Nat Med 17:692-699. CrossRef Medline

Andrabi SA, Umanah GK, Chang C, Stevens DA, Karuppagounder SS, Gagné JP, Poirier GG, Dawson VL, Dawson TM (2014) Poly(ADP-ribose) polymerase-dependent energy depletion occurs through inhibition of glycolysis. Proc Natl Acad Sci U S A 111:10209-10214. CrossRef Medline

Aprille JR (1993) Mechanism and regulation of the mitochondrial ATP$\mathrm{Mg} / \mathrm{P}(\mathrm{i})$ carrier. J Bioenerg Biomembr 25:473-481. CrossRef Medline

Aprille JR, Nosek MT, Brennan WA Jr (1982) Adenine nucleotide content of liver mitochondria increases after glucagon treatment of rats or isolated hepatocytes. Biochem Biophys Res Commun 108:834-839. CrossRef Medline

Attwell D, Laughlin SB (2001) An energy budget for signaling in the grey matter of the brain. J Cereb Blood Flow Metab 21:1133-1145. CrossRef Medline

Ben-Ari Y (1981) Epilepsy: changes in local glucose consumption and brain pathology produced by kainic acid. Adv Biochem Psychopharmacol 27: 385-394. Medline

Bernardi P, Krauskopf A, Basso E, Petronilli V, Blachly-Dyson E, Di Lisa F, Forte MA (2006) The mitochondrial permeability transition from in vitro artifact to disease target. FEBS J 273:2077-2099. CrossRef Medline

Bolshakov AP, Mikhailova MM, Szabadkai G, Pinelis VG, Brustovetsky N, Rizzuto R, Khodorov BI (2008) Measurements of mitochondrial pH in cultured cortical neurons clarify contribution of mitochondrial pore to the mechanism of glutamate-induced delayed $\mathrm{Ca} 2+$ deregulation. Cell Calcium 43:602-614. CrossRef Medline

Bonora M, Bononi A, De Marchi E, Giorgi C, Lebiedzinska M, Marchi S, Patergnani S, Rimessi A, Suski JM, Wojtala A, Wieckowski MR, Kroemer G, Galluzzi L, Pinton P (2013) Role of the c subunit of the FO ATP synthase in mitochondrial permeability transition. Cell Cycle 12:674683. CrossRef Medline

Brennan AM, Suh SW, Won SJ, Narasimhan P, Kauppinen TM, Lee H, Edling $\mathrm{Y}$, Chan PH, Swanson RA (2009) NADPH oxidase is the primary source of superoxide induced by NMDA receptor activation. Nat Neurosci 12: 857-863. CrossRef Medline

Brennan-Minnella AM, Shen Y, El-Benna J, Swanson RA (2013) Phosphoinositide 3-kinase couples NMDA receptors to superoxide release in excitotoxic neuronal death. Cell Death Dis 4:e580. CrossRef Medline

Brewer GJ, Torricelli JR, Evege EK, Price PJ (1993) Optimized survival of hippocampal neurons in B27-supplemented Neurobasal, a new serumfree medium combination. J Neurosci Res 35:567-576. CrossRef Medline

Budd SL, Nicholls DG (1996) Mitochondria, calcium regulation, and acute glutamate excitotoxicity in cultured cerebellar granule cells. J Neurochem 67:2282-2291. Medline

Chalmers S, Nicholls DG (2003) The relationship between free and total calcium concentrations in the matrix of liver and brain mitochondria. J Biol Chem 278:19062-19070. CrossRef Medline

Cheng Y, Sun AY (1994) Oxidative mechanisms involved in kainateinduced cytotoxicity in cortical neurons. Neurochem Res 19:1557-1564. CrossRef Medline

Chinopoulos C, Vajda S, Csanády L, Mándi M, Mathe K, Adam-Vizi V (2009) A novel kinetic assay of mitochondrial ATP-ADP exchange rate mediated by the ANT. Biophys J 96:2490-2504. CrossRef Medline

Clapham JC, Arch JR, Chapman H, Haynes A, Lister C, Moore GB, Piercy V, Carter SA, Lehner I, Smith SA, Beeley LJ, Godden RJ, Herrity N, Skehel M, Changani KK, Hockings PD, Reid DG, Squires SM, Hatcher J, Trail B, et al. (2000) Mice overexpressing human uncoupling protein-3 in skeletal muscle are hyperphagic and lean. Nature 406:415-418. CrossRef Medline

Contreras L, Satrústegui J (2009) Calcium signaling in brain mitochondria: interplay of malate aspartate NADH shuttle and calcium uniporter/mitochondrial dehydrogenase pathways. J Biol Chem 284:7091-7099. CrossRef Medline

Davidson SM, Yellon D, Duchen MR (2007) Assessing mitochondrial potential, calcium, and redox state in isolated mammalian cells using confocal microscopy. Methods Mol Biol 372:421-430. CrossRef Medline de la Fuente S, Fonteriz RI, de la Cruz PJ, Montero M, Alvarez J (2012) Mitochondrial free $[\mathrm{Ca}(2+)]$ dynamics measured with a novel low-Ca(2+) affinity aequorin probe. Biochem J 445:371-376. CrossRef Medline

del Arco A, Satrústegui J (2004) Identification of a novel human subfamily of mitochondrial carriers with calcium-binding domains. J Biol Chem 279:24701-24713. CrossRef Medline

Du L, Zhang X, Han YY, Burke NA, Kochanek PM, Watkins SC, Graham SH, Carcillo JA, Szabó C, Clark RS (2003) Intra-mitochondrial poly(ADPribosylation) contributes to $\mathrm{NAD}+$ depletion and cell death induced by oxidative stress. J Biol Chem 278:18426-18433. CrossRef Medline

Duan Y, Gross RA, Sheu SS (2007) Ca2+-dependent generation of mitochondrial reactive oxygen species serves as a signal for poly(ADP-ribose) polymerase-1 activation during glutamate excitotoxicity. J Physiol 585: 741-758. CrossRef Medline

Duchen MR (2012) Mitochondria, calcium-dependent neuronal death and neurodegenerative disease. Pflugers Arch 464:111-121. CrossRef Medline

Eliasson MJ, Sampei K, Mandir AS, Hurn PD, Traystman RJ, Bao J, Pieper A, Wang ZQ, Dawson TM, Snyder SH, Dawson VL (1997) Poly(ADPribose) polymerase gene disruption renders mice resistant to cerebral ischemia. Nat Med 3:1089-1095. CrossRef Medline

Fiermonte G, De Leonardis F, Todisco S, Palmieri L, Lasorsa FM, Palmieri F (2004) Identification of the mitochondrial ATP-Mg/Pi transporter: bacterial expression, reconstitution, functional characterization and tissue distribution. J Biol Chem 279:30722-30730. CrossRef Medline

Formentini L, Macchiarulo A, Cipriani G, Camaioni E, Rapizzi E, Pellicciari R, Moroni F, Chiarugi A (2009) Poly(ADP-ribose) catabolism triggers AMP-dependent mitochondrial energy failure. J Biol Chem 284:17668 17676. CrossRef Medline

Formentini L, Pereira MP, Sánchez-Cenizo L, Santacatterina F, Lucas JJ, Navarro C, Martínez-Serrano A, Cuezva JM (2014) In vivo inhibition of the mitochondrial $\mathrm{H}+$-ATP synthase in neurons promotes metabolic preconditioning. EMBO J 33:762-778. CrossRef Medline

Fouquerel E, Goellner EM, Yu Z, Gagné JP, Barbi de Moura M, Feinstein T, Wheeler D, Redpath P, Li J, Romero G, Migaud M, Van Houten B, Poirier GG, Sobol RW (2014) ARTD1/PARP1 negatively regulates glycolysis by inhibiting hexokinase 1 independent of NAD depletion. Cell Rep 8:18191831. CrossRef Medline

Fujikawa DG (2005) Prolonged seizures and cellular injury: understanding the connection. Epilepsy Behav 7 [Suppl 3]:S3-S11. CrossRef Medline

Gimenez-Cassina A, Martínez-François JR, Fisher JK, Szlyk B, Polak K, Wiwczar J, Tanner GR, Lutas A, Yellen G, Danial NN (2012) BAD-dependent regulation of fuel metabolism and K(ATP) channel activity confers resistance to epileptic seizures. Neuron 74:719-730. CrossRef Medline

Giorgio V, von Stockum S, Antoniel M, Fabbro A, Fogolari F, Forte M, Glick GD, Petronilli V, Zoratti M, Szabó I, Lippe G, Bernardi P (2013) Dimers of mitochondrial ATP synthase form the permeability transition pore. Proc Natl Acad Sci U S A 110:5887-5892. CrossRef Medline

Glancy B, Balaban RS (2012) Role of mitochondrial Ca2+ in the regulation of cellular energetics. Biochemistry 51:2959-2973. CrossRef Medline

Gleichmann M, Collis LP, Smith PJ, Mattson MP (2009) Simultaneous single neuron recording of $\mathrm{O} 2$ consumption, $[\mathrm{Ca} 2+]$ iand mitochondrial membrane potential in glutamate toxicity. J Neurochem 109:644-655. CrossRef Medline

Guo ZY, Li CZ, Li XJ, Wang YL, Mattson MP, Lu CB (2013) The developmental regulation of glutamate receptor-mediated calcium signaling in primary cultured rat hippocampal neurons. Neuroreport 24:492-497. CrossRef Medline

Hattori K, Kajimura M, Hishiki T, Nakanishi T, Kubo A, Nagahata Y, Ohmura M, Yachie-Kinoshita A, Matsuura T, Morikawa T, Nakamura T, Setou M, Suematsu M (2010) Paradoxical ATP elevation in ischemic penumbra revealed by quantitative imaging mass spectrometry. Antioxid Redox Signal 13:1157-1167. CrossRef Medline

Haumann J, Dash RK, Stowe DF, Boelens AD, Beard DA, Camara AK (2010) Mitochondrial free $[\mathrm{Ca} 2+]$ increases during ATP/ADP antiport and ADP phosphorylation: exploration of mechanisms. Biophys J 99:997-1006. CrossRef Medline

Jekabsons MB, Nicholls DG (2004) In situ respiration and bioenergetic status of mitochondria in primary cerebellar granule neuronal cultures exposed continuously to glutamate. J Biol Chem 279:32989-33000. CrossRef Medline

Jiang D, Zhao L, Clish CB, Clapham DE (2013) Letm1, the mitochondrial $\mathrm{Ca} 2+/ \mathrm{H}+$ antiporter, is essential for normal glucose metabolism and 
alters brain function in Wolf-Hirschhorn syndrome. Proc Natl Acad Sci U S A 110:E2249-E2254. CrossRef Medline

Kim SH, Lu HF, Alano CC (2011) Neuronal Sirt3 protects against excitotoxic injury in mouse cortical neuron culture. PLoS One 6:e14731. CrossRef Medline

Kioka H, Kato H, Fujikawa M, Tsukamoto O, Suzuki T, Imamura H, Nakano A, Higo S, Yamazaki S, Matsuzaki T, Takafuji K, Asanuma H, Asakura M, Minamino T, Shintani Y, Yoshida M, Noji H, Kitakaze M, Komuro I, Asano Y, et al. (2014) Evaluation of intramitochondrial ATP levels identifies G0/G1 switch gene 2 as a positive regulator of oxidative phosphorylation. Proc Natl Acad Sci U S A 111:273-278. CrossRef Medline

Koh DW, Lawler AM, Poitras MF, Sasaki M, Wattler S, Nehls MC, Stöger T, Poirier GG, Dawson VL, Dawson TM (2004) Failure to degrade poly(ADP-ribose) causes increased sensitivity to cytotoxicity and early embryonic lethality. Proc Natl Acad Sci US A 101:17699-17704. CrossRef Medline

Kristián T, Hopkins IB, McKenna MC, Fiskum G (2006) Isolation of mitochondria with high respiratory control from primary cultures of neurons and astrocytes using nitrogen cavitation. J Neurosci Methods 152:136143. CrossRef Medline

Lai Y, Chen Y, Watkins SC, Nathaniel PD, Guo F, Kochanek PM, Jenkins LW, Szabó C, Clark RS (2008) Identification of poly-ADP-ribosylated mitochondrial proteins after traumatic brain injury. J Neurochem 104:17001711. CrossRef Medline

Li V, Brustovetsky T, Brustovetsky N (2009) Role of cyclophilin D-dependent mitochondrial permeability transition in glutamate-induced calcium deregulation and excitotoxic neuronal death. Exp Neurol 218:171-182. CrossRef Medline

Llorente-Folch I, Rueda CB, Amigo I, del Arco A, Saheki T, Pardo B, Satrústegui J (2013) Calcium-regulation of mitochondrial respiration maintains ATP homeostasis and requires ARALAR/AGC1-malate aspartate shuttle in intact cortical neurons. J Neurosci 33:13957-13971. CrossRef Medline

Mandir AS, Poitras MF, Berliner AR, Herring WJ, Guastella DB, Feldman A, Poirier GG, Wang ZQ, Dawson TM, Dawson VL (2000) NMDA but not non-NMDA excitotoxicity is mediated by poly(ADP-ribose) polymerase. J Neurosci 20:8005-8011. Medline

Mayer ML, Westbrook GL (1987) Permeation and block of N-methyl-Daspartic acid receptor channels by divalent cations in mouse cultured central neurones. J Physiol 394:501-527. CrossRef Medline

McCord MC, Lorenzana A, Bloom CS, Chancer ZO, Schauwecker PE (2008) Effect of age on kainate-induced seizure severity and cell death. Neuroscience 154:1143-1153. CrossRef Medline

McLin JP, Thompson LM, Steward O (2006) Differential susceptibility to striatal neurodegeneration induced by quinolinic acid and kainate in inbred, outbred and hybrid mouse strains. Eur J Neurosci 24:3134-3140. CrossRef Medline

Nakano M, Imamura H, Nagai T, Noji H (2011) Ca2 + regulation of mitochondrial ATP synthesis visualized at the single cell level. ACS Chem Biol 6:709-715. CrossRef Medline

Nicholls DG (2008) Oxidative stress and energy crises in neuronal dysfunction. Ann N Y Acad Sci 1147:53-60. CrossRef Medline

Nichols BJ, Rigoulet M, Denton RM (1994) Comparison of the effects of $\mathrm{Ca} 2+$, adenine nucleotides and $\mathrm{pH}$ on the kinetic properties of mitochondrial $\mathrm{NAD}(+)$-isocitrate dehydrogenase and oxoglutarate dehydrogenase from the yeast Saccharomyces cerevisiae and rat heart. Biochem J 303:461-465. Medline

Nosek MT, Dransfield DT, Aprille JR (1990) Calcium stimulates ATP$\mathrm{Mg} / \mathrm{Pi}$ carrier activiry in rat liver mitochondria. J Biol Chem 265:84448450. Medline

Olney JW, Sharpe LG (1969) Brain lesions in an infant rhesus monkey treated with monsodium glutamate. Science 166:386-388. CrossRef Medline

O'Rourke B (2004) Evidence for mitochondrial K+ channels and their role in cardioprotection. Circ Res 94:420-432. CrossRef Medline

Pardo B, Contreras L, Serrano A, Ramos M, Kobayashi K, Iijima M, Saheki T, Satrústegui J (2006) Essential role of aralar in the transduction of small
$\mathrm{Ca}+$ signals to neuronal mitochondria. J Biol Chem 281:1039-1047. CrossRef Medline

Pittelli M, Formentini L, Faraco G, Lapucci A, Rapizzi E, Cialdai F, Romano G, Moneti G, Moroni F, Chiarugi A (2010) Inhibition of nicotinamide phosphoribosyltransferase: cellular bioenergetics reveals a mitochondrial insensitive NAD pool. J Biol Chem 285:34106-34114. CrossRef Medline Qian W, Van Houten B (2010) Alterations in bioenergetics due to changes in mitochondrial DNA copy number. Methods 51:452-457. CrossRef Medline

Qiu J, Tan YW, Hagenston AM, Martel MA, Kneisel N, Skehel PA, Wyllie DJ, Bading H, Hardingham GE (2013) Mitochondrial calcium uniporter Mcu controls excitotoxicity and is transcriptionally repressed by neuroprotective nuclear calcium signals. Nat Commun 4:2034. CrossRef Medline

Rangaraju V, Calloway N, Ryan TA (2014) Activity-driven local ATP synthesis is required for synaptic function. Cell 156:825-835. CrossRef Medline

Robinson KM, Janes MS, Beckman JS (2008) The selective detection of mitochondrial superoxide by live cell imaging. Nat Protoc 3:941-947. CrossRef Medline

Rodríguez-Moreno A, Sihra TS (2004) Presynaptic kainate receptor facilitation of glutamate release involves protein kinase $\mathrm{A}$ in the rat hippocampus. J Physiol 557:733-745. CrossRef Medline

Stout AK, Raphael HM, Kanterewicz BI, Klann E, Reynolds IJ (1998) Glutamate-induced neuron death requires mitochondrial calcium uptake. Nat Neurosci 1:366-373. CrossRef Medline

Tantama M, Martínez-François JR, Mongeon R, Yellen G (2013) Imaging energy status in live cells with a fluorescent biosensor of the intracellular ATP-to-ADP ratio. Nat Commun 4:2550. CrossRef Medline

Tomashek JJ, Glagoleva OB, Brusilow WS (2004) The Escherichia coli F1F0 ATP synthase displays biphasic synthesis kinetics. J Biol Chem 279:44654470. CrossRef Medline

Traba J, Del Arco A, Duchen MR, Szabadkai G, Satrústegui J (2012) SCaMC-1 promotes cancer cell survival by desensitizing mitochondrial permeability transition via ATP/ADP-mediated matrix Ca2 + buffering. Cell Death Differ 19:650-660. CrossRef Medline

Tymianski M, Charlton MP, Carlen PL, Tator CH (1993) Secondary Ca $2+$ overload indicates early neuronal injury which precedes staining with viability indicators. Brain Res 607:319-323. CrossRef Medline

Vander Jagt TA, Connor JA, Weiss JH, Shuttleworth CW (2009) Intracellular $\mathrm{Zn} 2+$ increases contribute to the progression of excitotoxic $\mathrm{Ca} 2+$ increases in apical dendrites of CA1 pyramidal neurons. Neuroscience 159:104-114. CrossRef Medline

Vincent P, Mulle C (2009) Kainate receptors in epilepsy and excitotoxicity. Neuroscience 158:309-323. CrossRef Medline

Virág L, Robaszkiewicz A, Rodriguez-Vargas JM, Oliver FJ (2013) Poly(ADPribose) signaling in cell death. Mol Aspects Med 34:1153-1167. CrossRef Medline

Yadava N, Nicholls DG (2007) Spare respiratory capacity rather than oxidative stress regulates glutamate excitotoxicity after partial respiratory inhibition of mitochondrial complex I with rotenone. J Neurosci 27:7310-7317. CrossRef Medline

Yang H, Yang T, Baur JA, Perez E, Matsui T, Carmona JJ, Lamming DW, Souza-Pinto NC, Bohr VA, Rosenzweig A, de Cabo R, Sauve AA, Sinclair DA (2007) Nutrient-sensitive mitochondrial NAD+ levels dictate cell survival. Cell 130:1095-1107. CrossRef Medline

Zamanian JL, Xu L, Foo LC, Nouri N, Zhou L, Giffard RG, Barres BA (2012) Genomic analysis of reactive astrogliosis. J Neurosci 32:6391-6410. CrossRef Medline

Zhang J, Dawson VL, Dawson TM, Snyder SH (1994) Nitric oxide activation of poly(ADP-ribose) synthetase in neurotoxicity. Science 263:687689. CrossRef Medline

Zhao Y, Araki S, Wu J, Teramoto T, Chang YF, Nakano M, Abdelfattah AS, Fujiwara M, Ishihara T, Nagai T, Campbell RE (2011) An expanded palette of genetically encoded Ca2+ indicators. Science 333:1888-1891. CrossRef Medline 